\title{
Las casas sobre el papel. Población, familia y comunidad en un padrón colonial. La Rioja, Gobernación del Tucumán (virreinato del Perú), siglo XVIII
}

\author{
Roxana Boixadós* \\ roxboixados@gmail.com \\ Judith Farberman** \\ jfarberman@unq.edu.ar
}

Recibido: marzo de 2014

Aprobado: noviembre de 2014

Resumen: Cumpliendo órdenes virreinales, el gobernador del Tucumán don Manuel Fernández Campero dispuso el empadronamiento de la población en 1767, con el doble fin de visitar a los pueblos de indios y de actualizar el cobro de la Bula de la Santa Cruzad. En el caso de La Rioja sólo se llevaron a cabo los registros del curato de Los Llanos y el de la ciudad y sobre éste nos abocamos en este trabajo. Elaborado por un juez comisionario con la asistencia de un Notario y el cura vicario, el padrón contiene valiosa información sobre su vecindad, identificando las unidades por casas en un ordenamiento que articulaba el prestigio y la notabilidad, la calidad y los recursos económicos. Nuestro objetivo es entrever las lógicas de clasificación y

* Universidad de Buenos Aires / Universidad Nacional de Quilmes / Consejo Nacional de Investigaciones Científicas y Técnicas de la República Argentina (CONICET). Centro de Estudios de Historia, Cultura y Memoria en Argentina (UNQ) Roque Sáenz Peña 352 (BI876BXD) Bernal, Buenos Aires, Argentina. (oo54-11) 4365-7100.

** Universidad de Buenos Aires / Universidad Nacional de Quilmes / Consejo Nacional de Investigaciones Científicas y Técnicas de la República Argentina (CONICET). Centro de Estudios de Historia, Cultura y Memoria en Argentina (UNQ) Roque Sáenz Peña 352 (BI876BXD) Bernal, Buenos Aires, Argentina. (0054-11) 4365-7100.

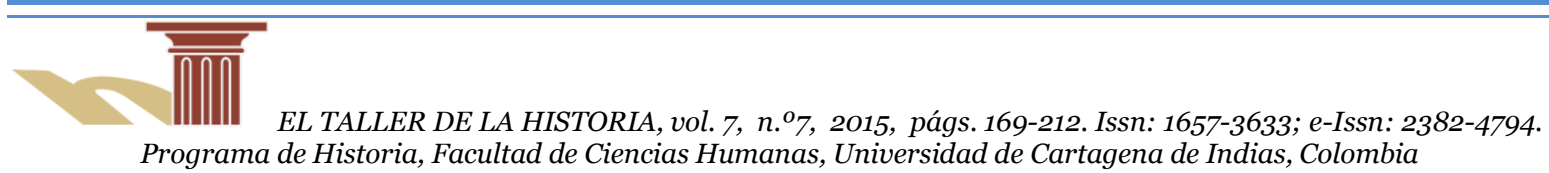


autorepresentación que esta fuente exhibe -y sobre todo las que encubre-, dando sentido a las jerarquías que regían la sociabilidad entre "patricios", "principales", criados y esclavos y vecinos de "inaveriguable nacimiento", miembros todos de una apartada comunidad colonial.

Palabras clave: La Rioja, vecindad, padrones coloniales

\title{
Drawing households on a paper. Population, family and community in a colonial census. La Rioja, Gobernación del Tucumán (Viceroyalty of Perú) XVIIIth century
}

\begin{abstract}
Fulfilling the orders of the Viceroy, don Manuel Fernandez Campero, governor of Tucuman commanded a population census in 1767 . One of the goals of the register was to renew the records that enabled the collection of duties at Bula de la Santa Cruzada. In the case of La Rioja, only the records of Los Llanos and the city itself were realised, therefore these are the objects of our study. Elaborated by a juez comisionario with the assistance of a notary and a priest, the census carries valuable information regarding the areas it covers, identifying households (casas) in a series that denotes the prestige, notability, and economic resources of its holders. Our objective is to glimpse the logic of classification and self representation that this source shows - but mostly those that it hides- by giving meaning to the hierarchies that governed the relations between "patricios", "principals", servants, slaves and neighbours of "inaveriguable nacimiento" (unknown origins), all members of a secluded colonial community.
\end{abstract}

Key words: La Rioja, vecindad, colonial census

\section{Introducción}

En 1767, el juez comisionario don Josep Antonio Baigorri de la Fuente llegó a La Rioja con una doble misión. Por un lado, la de visitar las reducciones de indios para actualizar el cobro de tributos; por el otro, la de confeccionar de una nómina completa de los habitantes de la ciudad a fin de identificar a los compradores de la Bula

Dossier: Cuestionando las fuentes de archivos: padrones de población, familias y sociedades coloniales en Iberoamérica, ss. XVIII-XIX 
de Cruzada. ${ }^{1}$ Eran tareas de difícil cumplimiento dada la dilatada extensión de los curatos, el clima tórrido y seco, y las considerables distancias que separaban a los pueblos de indios dispersos en el corazón de los valles y al pie de las costas serranas.

Otros obstáculos se sumaron a poco de comenzar: apenas concluida su labor en los pueblos de indios del curato de Los Llanos, en el sudeste de la jurisdicción, el asistente de Baigorri cayó enfermo. Varado en la ciudad cabecera, el juez comisionario esperó -en vano- que los curas doctrineros le enviaran los status animorum oportunamente solicitados para sumarlos al del curato llanista, el único en su poder. Quizás para su alivio, en el interín supo Baigorri del cese de funciones del gobernador Fernández Campero y procedió a suspender las actuaciones. Por estos motivos, sólo los padrones del curato rural de Los Llanos y el de la ciudad pudieron concretarse -en los tres largos meses estivales de 1767- y llegar hasta nosotros, acompañados ambos de copiosas notas y observaciones que llenan en conjunto 145 fojas. En este artículo, nos ocuparemos de manera central del padrón citadino, asociado a la venta de la Bula, para luego establecer algunas relaciones con el padrón rural que hemos analizado en otra parte. ${ }^{2}$

Desde la perspectiva de la demografía histórica, los documentos labrados por Baigorri de la Fuente tendrían escaso valor. Está ausente en todos los casos el dato de la edad (apenas si se diferencia a los párvulos menores de siete años del resto de los individuos anotados) y tanto los apellidos (especialmente los de las mujeres) como las categorías socio-étnicas, relativamente habituales en los conteos de esta época, son erráticamente registrados. En la sección rural del censo, tampoco resulta siempre nítida la diferenciación de unidades residenciales. Sin embargo,

\footnotetext{
${ }^{1}$ Archivo Histórico de la Provincia de Córdoba (AHPC), Escribanía 2, leg.37, exp.21 (1768), ff.348423.

2 Roxana Boixadós y Judith Farberman, "Oprimidos de muchos vecinos en el paraje de nuestra habitación'. Tierra, casa y familia en Los Llanos de La Rioja colonial”, en Boletín del Instituto Ravignani n. ${ }^{\circ}$ 31, Buenos Aires, Facultad de Filosofía y Letras UBA, 2009, pp.11-31; "Clasificaciones mestizas. Una aproximación a la diversidad étnica y social en Los Llanos riojanos. Siglo XVIII", en Judith Farberman y Silvia Ratto (coords.), Historias mestizas en el Tucumán colonial y en las pampas, Buenos Aires, Biblos, pp.79-114.
}

Dossier: Cuestionando las fuentes de archivos: padrones de población, familias y sociedades coloniales en Iberoamérica, ss. XVIII-XIX 
confrontados en el interior de un corpus más amplio y ponderada su información cualitativa, estos materiales protoestadísticos revisten un valor incalculable como expresión de imaginarios sociales y es en esta clave que los pensaremos aquí.

Decía Ángel Rama que por la naturaleza de su génesis y por su arquitectura las ciudades barrocas habían trasladado un orden social a una realidad física. En sus palabras

mucho más importante que la forma damero [...] es el principio rector que tras ella funciona y asegura un régimen de trasmisiones: de lo alto a lo bajo, de España a América, de la cabeza del poder -a través de la estructura social que él dispone- a la conformación física de la ciudad, para que la distribución del espacio urbano asegure y conserve la forma social. ${ }^{3}$

Algo similar expresaba Bernardo Canal Feijoo sobre el carácter performativo de las urbes coloniales que "en vez de fundadas en el paisaje eran cuadriculadas en el suelo". ${ }^{4}$ A su manera, también Baigorri de la Fuente -con ayuda de inestimable colaboración local- dibujó la ciudad de La Rioja en un padrón de habitantes. A partir de la cuadrícula censal, ensayó una suerte de cartografía social, desplegando en el papel un diseño consensuado de un espacio urbano atravesado por jerarquías estamentales, religiosas y de género. El censista dispuso las casas sobre el papel y en ellas a sus moradores; dicha disposición era intencionada y, como se verá, no se atenía a criterios estrictamente geográficos. Tratamos, entonces, con una pieza de singular valor heurístico, apta para penetrar las representaciones que la élite de una pequeña ciudad casi aldeana tenía de sí misma a mediados del siglo XVIII.

Como es sabido, en aquella centuria las políticas borbónicas pusieron en marcha sofisticados engranajes burocráticos orientados a conocer, clasificar y ordenar las complejas y móviles sociedades coloniales americanas. ${ }^{5}$ Sin embargo, no

${ }^{3}$ Angel Rama, La ciudad letrada, Montevideo, Arca, 1998, p.21.
4 Bernardo Canal Feijoo, “Teoría de la ciudad argentina”, en Ensayos sobre cultura y territorio,
Buenos Aires, UNQ/Prometeo 3010, 2010, p.143.
${ }^{5}$ La bibliografía sobre el tema es copiosa. Destacamos, entre otros textos, Juan Carlos Estenssoro
Fuchs, "Los colores de la plebe razón y mestizaje en el Perú colonial”, en AAVV, Los cuadros de mes-
tizaje del Virrey Amat. La representación etnográfica en el Perú colonial, Lima, Museo de Arte de

Dossier: Cuestionando las fuentes de archivos: padrones de población, familias y sociedades coloniales en Iberoamérica, ss. XVIII-XIX 
son comunes para la gobernación del Tucumán documentos que, como el que nos convoca, además de dar cuenta del vecindario y de los moradores registraran también los bienes y propiedades de su sector más privilegiado. A ello, justamente, apuntaba el padrón: a identificar a los vecinos en condiciones de comprar indulgencias y comprobar de paso si la aludida "falta de recursos" explicaba la merma en la recaudación de este ramo.

A partir de 1750, y como parte del impulso reformista, el gravamen eclesiástico de origen medieval conocido como Bula de Santa Cruzada devino en un impuesto secular que cobraban los oficiales reales. En el Tucumán, su recaudación -a cargo de eclesiásticos y de funcionarios civiles- era destinada a sostener la defensa de fuertes y presidios en la frontera de Córdoba. ${ }^{6} \mathrm{~A}$ diferencia de los padrones nominativos vinculados a la venta de indulgencias realizados en España, el que nos ocupa registra en primer lugar a los habitantes de la ciudad de La Rioja y curato rectoral y a sus familias, relevando sus condiciones socio-económicas para luego proceder a consignar a quienes estaban en condiciones de adquirir -por dos reales o menos- la indulgencia de "vivos". ${ }^{7}$ Ello explica el particular registro de la pobla-

Lima, 1999, pp.67-107; John Chance y William B. Taylor, "Estate and Class in a Colonial City: Oaxaca in 1792", in Comparative Studies in Society and History n. ${ }^{\circ} 19$, Cambridge, Society for the Comparative Study of Society and History, 1977, pp.454-87; Nicholas Hudson, "From 'Nation' to 'Race': The Origin of Racial Classification in Eighteenth-Century Thought", in Eigteenth Century Studies vol.29, n. ${ }^{\circ}$ 3, Baltimore, John Hopkins University Press, 1996, pp.247-264; Jean Paul Zuñiga, "Morena me llaman...”. Exclusión e integración de los afroamericanos en Hispanoamérica: el ejemplo de algunas regiones del antiguo virreinato del Perú (siglos XVI a XVIII)", en Berta Ares Queija y Alessandro Stella (coords.), Negros, mulatos, zambaigos. Derroteros africanos en los mundos ibéricos, Sevilla, Escuela de Estudios Hispanoamericanos/CSIC, 2000, pp.105-122. Para el interior del territorio hoy argentino, María Florencia Guzmán, Los claroscuros del mestizaje. Negros, indios y castas en la Catamarca colonial, Córdoba, Encuentro Grupo Editor, 2010, Ana María Bascary, Familia y vida cotidiana. Tucumán a fines de la colonia, Facultad de Filosofía y Letras, Universidad de Tucumán, 1999.

${ }^{6}$ Bárbara Aramendi, "El ramo de bulas de la Santa Cruzada en el Tucumán colonial”, en Diálogo Andino n. ${ }^{\circ} 33$, Arica, Universidad de Tarapacá, 2009, p.63.

7 José Ojeda Nieto, "La población de castilla y León en el siglo XVII: un intento de aproximación demográfica a través de la Bula de la Santa Cruzada”, en Studia Histórica, Historia Moderna n. $^{\circ} 22$, Salamanca, Universidad de Salamanca, 2000, pp.109-144 y "La población del Reino de Valencia en el siglo XVII según la Bula de la Santa Cruzada”, en Estudis, Revista de Historia Moderna n. ${ }^{\circ} 32$, Barcelona, Universitat di Valencia, 2006, pp.263-290; Manuel Fernández Cháves, "La Villa de

Dossier: Cuestionando las fuentes de archivos: padrones de población, familias y sociedades coloniales en Iberoamérica, ss. XVIII-XIX 
ción local que puso en juego jerarquías socioeconómicas, relaciones sociales, apellidos, propiedades, caudal y "calidad" para estructurar una clasificación. Empero, este "quién es quién" proyecta una elaboración entretejida por saberes, pertenencias e identificaciones de las que participaban tanto los miembros de esta sociedad como el juez que los empadronó y los agentes que le asistieron en la tarea. Por tanto, para comprender el entramado de esta construcción, será preciso dar cuenta del perfil de ciertos personajes que cumplieron el rol de mediadores e instrumentos de expresión de un cierto orden social.

\section{La Rioja, la "muy noble ..."}

Tentado por el espejismo de un fabuloso desarrollo minero en el cerro de Famatina, el gobernador del Tucumán Juan Ramírez de Velasco fundó en 1591 la ciudad de La Rioja. Los vecinos guardaban una rancia memoria de los hechos de la conquista, de su lucha contra los nativos rebeldes y de sus sacrificados esfuerzos por erigir una sociedad señorial en los confines de la gobernación. En un gesto expresivo de su engreimiento y aspiraciones a "valer más", sus vecinos solicitaron de inmediato a la Audiencia de Charcas el título de "muy noble", ya concedido a la ciudad de Santiago del Estero, la primera fundación estable de la Argentina y cabecera de la gobernación. Aunque la gracia no les fue concedida, los beneméritos guardaron el orgullo de haber participado de la gesta de creación de una "nueva" Rioja, viñatera como su homónima castellana y protegida además por "todos santos". 8

Lebrija a finales del reinado de Felipe III. El padrón de Bula de Santa Cruzada de 1620”, en Revista de Humanidades n. ${ }^{\circ}$ 16, Sevilla, Universidad de Sevilla, 2009, pp.59-89.

8 El nombre de Todos Santos de la Nueva Rioja fue elegido según el fundador "por cumplir con todos y haberlos tomado por intercesores y, con licencia de vuestra Majestad, por cumplir con mi patria". "Carta a S. M. de Juan Ramírez de Velasco, Santiago de Tucumán, octubre 20 de 1591", en Roberto Levillier, Nueva Crónica de la conquista de Tucumán, tomo III (1574-1600), Varsovia, Colección de Publicaciones Historia de la Biblioteca del Congreso Argentino, 1926, p.339. La Real Audiencia de Charcas le envió al cabildo copias de varias ordenanzas reales para que éste pudiera hacerlas valer ante los gobernadores, entre ellas la que reconocía a los fundadores de ciudades el goce de las encomiendas hasta la tercera vida, derecho que los feudatarios demandaron y obtuvieron.

Dossier: Cuestionando las fuentes de archivos: padrones de población, familias y sociedades coloniales en Iberoamérica, ss. XVIII-XIX 
$\mathrm{El}$ acto fundacional y la conquista de los naturales convirtieron a sus autores en encomenderos, señores de vasallos, vecinos y capitulares, aunque algunos de ellos ni siquiera supieran leer ni escribir..$^{9}$ Los comienzos fueron difíciles y la enorme distancia que separaba La Rioja de otras ciudades españolas se hizo sentir de inmediato, en particular su vulnerabilidad frente a los ataques de las poblaciones indígenas aún en proceso de conquista. Como contrapartida, los grupos ya sometidos fueron tratados con extrema crueldad. Las cartas al Rey del gobernador Alonso de Rivera de 1608 describen las vejaciones de todo tipo que permitían a mayordomos y pobleros extraer de los encomendados bajo su tutela las rentas tan esperadas. El cultivo de trigo, el mantenimiento de las huertas y los hilados de algodón y de lana eran exigidos como servicio personal y no perdonaban a ningún miembro de la familia indígena. ${ }^{10}$ En este sentido, la violencia de la conquista y la que teñía las cotidianas relaciones interétnicas en el mundo del trabajo resulta incongruente con los generosos y delicados trazos de la descripción del carmelita Antonio Vázquez de Espinosa de 1620:

fundada en un sitio llano y apasible, de buen cielo, su temple es caliente, tiene esta ciudad mas de dos leguas de guertas de naranjos y los demás árboles frutales de España y otros de la tierra por donde se entra, que como los naranjos por el buen temple de la tierra están siempre cubiertos y cargados de azajar, está aquella entrada por espacio de las dos leguas, demás de ser alegre y hermosa vista por estar los árboles todo el año cargados de frutas y con gran frescor y verdura que parece aquel parage el paraíso terrenal, o un pedaso de cielo

\footnotetext{
9 En 1600, el gobernador Mercado de Peñaloza envió al cabildo riojano varias ordenanzas que recordaban que no podían ser electos para los oficios los deudores a la Real Hacienda, los desterrados o con causas criminales pendientes y quienes no supieran leer ni escribir. Leídas en el Cabildo al año siguiente, el Alguacil Mayor Sebastián de Loria respondió que "los que han gobernado en esta república, aunque no saben leer ni escribir son capaces, pues son servidores de su Magestad y feudatarios". "Cabildo, Auto del capitán Juan Bautista Muñoz (teniente de gobernador)", en Revista de la Junta de Historia y Letras de La Rioja $\mathrm{n}^{\circ}{ }_{2}$, La Rioja, Junta de Historia y Letras, 1942, pp.23-25.

${ }^{10}$ Carta al Rey del gobernador de Tucumán Alonso de Ribera, Santiago del Estero, 11 de febrero de 1608, en Ricardo Rodríguez Molas, Los sometidos de la conquista. Argentina, Bolivia, Paraguay, Buenos Aires, CEAL, 1985, pp.206-217.
}

Dossier: Cuestionando las fuentes de archivos: padrones de población, familias y sociedades coloniales en Iberoamérica, ss. XVIII-XIX 
La relación del religioso también hacía referencia a los 250 vecinos españoles -que quintuplicaban al grupo fundador- a la iglesia parroquial, a los conventos de Santo Domingo y San Francisco, a la flamante Compañía de Jesús, a las viñas, huertas y sembrados que regaba la gran acequia y a los más distantes potreros de vacunos y mulares. Más lejos todavía, en sus pueblos de encomienda, "indios de buena razón" producían hilados y tejidos de lana y algodón que aportaban un nuevo rubro al abanico de producciones regionales. ${ }^{11}$

Elegimos esta descripción por ser la única halagüeña conocida para La Rioja. Y no casualmente, se ha sostenido que Vázquez de Espinosa nunca estuvo allí. ${ }^{12}$ En cambio, existe mayor certeza sobre las dificultades atravesadas por la ciudad entre 1630 y 1660, años marcados por los levantamientos nativos, la agudización de la violencia y el consecuente estado de alerta instalado en las familias hispano criollas. En aquellos tiempos, y luego de arrasar la cercana San Juan Bautista de la Rivera, la avanzada de los indígenas rebeldes, aliados con grupos de otras regiones, llegó a las puertas mismas de la ciudad, destruyó la toma de agua y la acequia principal. Aunque la rebelión fue sofocada, los costos fueron muy altos para ambas partes; los rebeldes sufrieron importantes bajas y perdieron tierras al ser trasladados a reducciones o pueblos de indios, mientras que los españoles debieron habituarse a accesos limitados o condicionados a la mano de obra. En todo caso, la producción regional -siempre de pequeña escala y muy dependiente de los vaivenes del mercado potosino y de la demanda de ciudades lejanas como Córdoba o Buenos Airesencontró dificultades para recuperarse y la entera jurisdicción quedó desde entonces relativamente aislada.

Este complejo proceso de conquista y reconquista modeló indeleblemente el perfil de la élite local. Las rebeliones indígenas retroalimentaron los valores asociados a la guerra y con ellos los "méritos y servicios" habidos con sangre y sacrificio. A medida que las encomiendas caducaban y se convocaban las oposiciones para su

\footnotetext{
11 Antonio Vázquez de Espinosa, Compendio y descripción de las Indias Occidentales, Washington, Smithsonian Miscellaneous Collection, 1948, p.627.

12 Según Félix Luna, que había comentado precedentemente esta fuente, "Vázquez de Espinosa jamás estuvo en La Rioja y en consecuencia, su idílica descripción de la ciudad se habrá fundado en relatos de terceros"; "Explico [...]" (Introducción), Temas de Historia Colonial de La Rioja, La Rioja, Nexo, 2004, p.11.
}

Dossier: Cuestionando las fuentes de archivos: padrones de población, familias y sociedades coloniales en Iberoamérica, ss. XVIII-XIX 
reasignación, los descendientes de conquistadores hacían valer las acciones guerreras propias y de sus antepasados, decisivas para acceder a la institución clave para hacerse de mano de obra y connotar la pertenencia a la élite. Así pues, como en el resto del Tucumán, los "vecinos y feudatarios" desplegaron actividades empresariales que descansaban sobre la servidumbre indígena. Y, aunque bien pronto las encomiendas se fueron empequeñeciendo -no sólo por las guerras, sino también por el mestizaje y el abandono de los pueblos de reducción- la conservación de sus remanentes preservó durante varias décadas la posición de ciertas familias de beneméritos dentro de la élite.

La historia local reconoce un puñado de apellidos paradigmáticos que consagraban la pertenencia a aquel grupo fundador. Bazán de Pedraza, Villafañe y Guzmán, Toledo Pimentel, Ramírez de Velasco, Luna y Cárdenas, Ávila Barrionuevo, Brizuela, Herrera y Guzmán -entre otros- evocaban a conquistadores, fundadores y heroicos guerreros, primeros propietarios de haciendas y estancias, encomenderos y dueños de esclavos, pequeños empresarios con conexiones comerciales dentro y fuera de la gobernación. Durante décadas estos apellidos se repitieron entre los integrantes del cabildo acompañándose de grados militares, ya que los feudatarios y los jefes de familia más importantes solían ser también maestres de campo aunque no siempre hubieran asistido ellos mismos a las campañas de pacificación del valle de Calchaquí o de la frontera del Chaco.

Entre fines del siglo XVII y comienzos del siguiente, los conflictos y luchas por el control de las encomiendas y de los cargos capitulares fueron acrecentándose. Dos cuestiones quedaron en evidencia: por un lado, la construcción de grupos de poder articulados en torno a las familias de mayor prestigio y recursos económicos; por el otro, la escasa renovación de la contextura de la elite, que sólo había incorporado en su seno -a través de matrimonios estratégicos- a unos pocos peninsulares y criollos de otras ciudades. De esta suerte, son raros los apellidos nuevos que las fuentes registran y que, en la descendencia, estarían asociados a los locales tradicionales. ${ }^{13} \mathrm{El}$ recurso a una reiterada endogamia fue tejiendo lazos de paren-

${ }^{13}$ Armando Raúl Bazán, Historia de La Rioja, Buenos Aires, Plus Ultra, 1979; Jorge A. Serrano Redonnet, La sangre del conquistador Juan Gregorio Bazán. Buenos Aires, Ediciones Dunken, 1997;

Dossier: Cuestionando las fuentes de archivos: padrones de población, familias y sociedades coloniales en Iberoamérica, ss. XVIII-XIX 
tesco entre varias familias, extendiendo los apellidos emblemáticos y creando formas combinadas que evocaban en simultáneo a más de un ancestro.

No obstante lo dicho, las limitaciones del contexto, la propia lógica del parentesco y del régimen de herencia fueron abriendo grietas, habilitando el desplazamiento de ciertos grupos de descendencia y propiciando la formación de dos sectores jerarquizados dentro de la elite. El primero estaba integrado por familias que concentraban los atributos de poder económico, sociopolítico y simbólicos de esa pertenencia; el segundo, aunque relacionado con el anterior por parentesco y vínculos de dependencia, sólo conservaba el acceso a ciertos espacios de prestigio y en menor medida a los caudales correspondientes a su status social. Sin embargo, la adscripción de unos y otros a colectivos familiares fuertemente corporativos que se preciaban de descender de los primeros conquistadores y fundadores por los "cuatro abolengos" fue muy significativa. ${ }^{14}$

Por si algo faltaba para consagrar la distinción, algunas familias riojanas fundaron mayorazgos por vía testamentaria, propiedades identificadas por un apellido emblemático que por generaciones se transmitían indivisas a un solo usufructuario. Siguiendo esta lógica, en 1663 el general don Pedro Nicolás de Brizuela creó el vínculo de Sañogasta, en 1717 el maestre de Campo don Juan Gregorio Bazán de Pedraza y Texeda (en ese entonces gobernador del Paraguay) los mayorazgos de Totox y Anillaco, y en 1723 doña Josefa Luis de Cabrera instituyó el de Cochangasta. La estrategia buscaba evitar el "deslustre" de las familias que habían alcanzado

Félix Luna, "Planes para La Rioja colonial” (1978), Temas de Historia colonial de La Rioja, La Rioja Nexus, 2004, pp.66-114.

${ }^{14}$ Esta noción ya se encuentra prefigurada hacia finales del siglo XVII y comienzos del XVII, y se refiere al prestigio (y honor) transmitido a través de la sangre a sus descendientes a partir de los antepasados fundadores, cuatro para cada "ego" de referencia, es decir, los abuelos. Los apellidos eran obviamente los marcadores de identidad de este atributo distintivo. Roxana Boixadós, Tierra de hombres de cuatro abolengos. Parentesco y familia en La Rioja colonial, Tesis de Maestría inédita, Museo Nacional, Universidad Federal de Rio de Janeiro, 1996. Quarleri analiza los comportamientos faccioso de la elite riojana en el contexto de la liquidación de los bienes de la Compañía de Jesús y la formación de la Junta de temporalidades (1770) mostrando que los peninsulares estaban fuertemente comprometidos con los intereses de sus familias políticas al mismo tiempo que gestaban sus propias alianzas desde sus puestos de funcionarios estatales. Lía Quarleri, "Elite local, burocracia y reformas borbónicas: La administración de temporalidades de la Rioja”, en Población y Sociedad n. ${ }^{\circ} 8-9$, Tucumán, Fundación Yocavil, 2000-2001, pp.177-210. 
una buena posición económica y social y que veían en el sistema distributivo de la herencia una amenaza que dispersaba los bienes en cada generación. ${ }^{15}$ Como veremos en adelante, esta presentación sintética y algo esquemática de la notabilidad riojana habría de adquirir matices y claroscuros en las décadas siguientes.

De hecho, las primeras décadas del siglo XviII fueron cruciales para la redefinición de la elite riojana; pocas familias lograron mantener el monopolio de las de por sí escasas encomiendas y tuvieron la versatilidad para diversificar sus actividades participando del comercio o de la ganadería aprovechando los vínculos de parentesco con familias de elites vecinas (Córdoba, Tucumán, Salta). En las chacras citadinas, dedicadas al cultivo de la vid y huertas de frutos de Castilla, estas familias contaban con "gente de servicio" y entre ellos, un número creciente de esclavos que también asistían en las propiedades de algunas órdenes religiosas. ${ }^{16}$

Como parte de este proceso, un gradual estrechamiento comenzó a atribular a la vecindad riojana, dando lugar a una serie de conflictos por el control de los oficios. El gobernador don Esteban de Urízar tuvo que mediar y resolver varios litigios, sobre todo aquellos que se desataban en el primer cabildo anual, cuando se

\footnotetext{
${ }^{15}$ La creación de mayorazgos fue excepcional en el territorio de la Gobernación del Tucumán donde además de los 4 nombrados se fundaron otros dos en la vecina jurisdicción de Catamarca (cuya élite estaba emparentada con la riojana) y uno en Jujuy. De todos ellos el de más prolongada existencia fue el de Sañogasta que se conservó indiviso hasta mediados del siglo Xx. Hemos estudiado estas instituciones en investigaciones anteriores; cfr. Roxana Boixadós, "Transmisión de bienes en familias de elite. Los mayorazgos de La Rioja colonial”, en Andes, Antropología e Historia n. ${ }^{\circ} 10$, Salta, CEPIHA, 1999, pp.51-78, y "Familia, herencia e identidad. Las estrategias de reproducción de la elite en La Rioja colonial (gobernación del Tucumán, siglo XVII y principios del XVIII)", en Revista de Demografía Histórica n. ${ }^{\circ} \mathrm{XIX}$, II, Zaragoza, ADEH, 2001, pp.147-181; "Cuñados no son parientes sino accidentes." Conflictos familiares en torno a la herencia de Cochangasta (La Rioja, siglo XVIII), en Anuario n. ${ }^{\circ}$ 1, Córdoba, Centro de Estudios Históricos Prof. Carlos S.A. Segreti, 2001, pp.39-60. También ver Roxana Boixadós y Judith Farberman, "Tres formas de propiedad indivisa en La Rioja colonial. Mayorazgos, pueblos de indios y campos comuneros, siglos XVII a XIX”, en Revista de Ciencias Sociales $n .^{\circ} 27$, Bernal, Universidad Nacional de Quilmes, 2015, en prensa.

16 La incorporación de mano de obra esclava en la jurisdicción comienza a ser significativa en el siglo XVIII, si bien desde los inicios de la colonización éstos estuvieron presentes, ver Víctor Hugo Robledo, La Rioja negra, Nexo Grupo Editor, La Rioja, 2004; María Florencia Guzmán, "Familias de los esclavos en La Rioja tardocolonial. 1760-1810", en Andes. Antropología e Historia n. ${ }^{\circ}$, Salta, CEPIHA, 1997, pp.225-242.
}

Dossier: Cuestionando las fuentes de archivos: padrones de población, familias y sociedades coloniales en Iberoamérica, ss. XVIII-XIX 
elegían los alcaldes ordinarios. Urízar obligó a las dos principales familias que se disputaban estos oficios (Villafañes y Bazanes) a firmar una "concordia" que estipulaba, entre sus varias cláusulas, la alternancia de miembros de una u otra familia en los cargos de alcalde de primer y de segundo voto. La concordia instituyó una paz duradera -aunque siempre en tensión-, en la que los matrimonios y las nuevas generaciones diluyeron las antiguas rivalidades al tiempo que se reconfiguran otras.

Durante el desarrollo de los conflictos -que se habían iniciado a fines del siglo anterior- la vecindad riojana procuró mantenerse al margen a pesar de que de un modo u otro las redes parentales los vinculaban a ambos contendientes. Algunos se alejaron de la ciudad originando un fenómeno de más largo aliento: la progresiva instalación de familias en sus propiedades rurales. La vecindad -decía Urízar en 1708- se reducía a 159 "españoles" que moraban en "despobladas y arruinadas" viviendas. Las sempiternas dificultades para reactivar el comercio y las limitaciones en la producción de granos, vinos y la cría de ganados eran responsables de la pobreza, del estancamiento y la ruralización. ${ }^{17}$

Nos aproximamos así al momento del censo que, al menos por dos razones, señala una inflexión en la historia regional. Por un lado, una epidemia había diezmado hacia 1766 la población riojana, empeorando las penurias que, según los vecinos, eran el pan cotidiano desde la fundación misma. Dos informes sucesivos ambos elevados al Rey a través del procurador- pintaban la situación de la ciudad y su curato en tonos más sombríos que nunca. ${ }^{18}$ Los capitulares pedían ser eximidos

17 Roxana Boixadós, “Asuntos de familia, cuestiones de poder. La 'concordia' en el cabildo de La Rioja (gobernación del Tucumán) en 1708” in Colonial Latin American Historical Review vol.2, n. ${ }^{\circ} 13$, Albuquerque, Spanish Colonial Research Center, 2005, pp.147-171. El informe del gobernador Urízar forma parte de una carta dirigida al Rey, fechada en Salta el 22 de noviembre de 1708, Archivo general de Indias, Charcas 210. Los problemas con el abasto del agua, que llegaba a las chacras a través de estrechos canales siguiendo turnos, pronto dio lugar al dictado de ordenanzas para su administración -una en 1611 (Alfaro) y dos en el siglo XVIII- que no evitaron la existencia de conflictos. Gastón Doucet, "Las ordenanzas de aguas para La Rioja del visitador don Francisco de Alfaro (1611)", en Revista de Historia del Derecho n. ${ }^{\circ}$, Buenos Aires, Instituto de Historia del Derecho, 1976, pp.397-425 y del mismo autor "La administración de aguas en La Rioja bajo el régimen español: aportes para su historia" en Revista de Historia del Derecho n. ${ }^{\circ} 11$, Buenos Aires, Instituto de Historia del Derecho, 1983, pp.491-506.

18 No hemos consultado de primera mano el informe de 1766 -que reproducía una descripción extraviada o desatendida de 1760-. Sabemos de su contenido gracias al artículo de Edberto Acevedo, "La Rioja hace dos siglos", en Investigaciones y Ensayos n. ${ }^{\circ}$, Buenos Aires, Academia Nacional de

Dossier: Cuestionando las fuentes de archivos: padrones de población, familias y sociedades coloniales en Iberoamérica, ss. XVIII-XIX 
de la contribución de 500 mulas exigidas desde la cabecera de la gobernación visto el flagelo de la peste que se había llevado 600 almas "de todas clases". La entidad de la catástrofe y la miseria de los pobladores -aseguraban calificados testigos seculares y eclesiásticos- habían obligado a la matriz y a los conventos a enterrar "de limosna" al sinfín de difuntos. Por otra parte, ya se encontraba en ciernes la expulsión de los jesuitas cuyo colegio reunía ingentes bienes en la jurisdicción riojana. ${ }^{19}$ Las consecuencias de este embate fueron visibles pocos años más tarde de levantado el padrón que nos concierne. No obstante, es de notar que el provincial de los ignacianos se negó a presentarle a Baigorri la nómina de los criados libres y esclavos de la compañía por lo cual más de 300 individuos fueron omitidos del padrón.

Basten estas pocas pinceladas para imaginar el clima que se vivía en la ciudad mediterránea a la llegada de Baigorri de la Fuente. ${ }^{20}$ Es previsible el recelo con el cual el cordobés fue recibido -recelo mutuo, ya que el juez comisionario tampoco ahorró palabras sobre la tacañería de los vecinos riojanos- y la magnitud de la tarea que le esperaba.

Antes de ingresar de lleno en los datos del padrón, son necesarias dos aclaraciones. La primera es que la geografía que albergaba a la población registrada era la del curato rectoral, que incluía el casco urbano y la zona rural aledaña que hospedaba el antiguo pueblo de indios de Sanagasta y las estancias del Carrizal y Amil-

la Historia, 1968, pp.191-213. La información de 1765 se encuentra en Archivo Histórico de la Provincia de Córdoba (AHPC), Cajas de Gobierno, tomo IV, legajo 67 (1765), ff.508r.-513v.

${ }^{19}$ Sobre las propiedades de los jesuitas en La Rioja, ver Lía Quarleri, "La administración laica de los bienes de los jesuitas de La Rioja: producción, ingresos y malversación fiscal", en Mundo Agrario vol.1, n. ${ }^{\circ}$, La Plata, Universidad Nacional de La Plata, 2001, pp.1-17. On line http://www.mundoagrario.unlp.edu.ar/rt/printerFriendly/MAvo1no2ao2/1573.

${ }^{20}$ Quien, por otra parte, se encontraba muy ofuscado porque solamente tres vecinos riojanos habían tomado bulas de a dos pesos en 1766; las restantes 189 indulgencias vendidas eran de entre tres reales y medio y dos reales "quedándose la mayor parte de este vecindario sin tomarla, lo qe ha sucedido de tiempo inmemorable por la gravisima omision de los tesoreros y comisarios de esta ciudad, omitiendo todos, hasta la presente todas las dilijencias christianas y medios conducentes que en cumplim.to de dhos cargos deben practicar; de la que se ha orijinado el abuso que se ha introducido de estar operando (a lo menos la gente pleve y parte de la que no lo es) el berse en peligro de muerte para comprar dha bulla”. AHPC, 2. 37.21 (1768). f.27.

Dossier: Cuestionando las fuentes de archivos: padrones de población, familias y sociedades coloniales en Iberoamérica, ss. XVIII-XIX 
gancho. Según el citado informe de 1766, la ciudad en sentido estricto apenas si abarcaba siete cuadras cuadradas, con sus pocas casas decentes y una mayoría de "ranchos de pobre fábrica" con techos "de heno y barro". ${ }^{21} \mathrm{El} \mathrm{mismo} \mathrm{Baigorri,} \mathrm{por}$ otra parte, se encargó de aclarar que sus registros correspondían a quienes residían "en esta ciudad, sus inmediaciones y extramuros" aunque sólo diferenciara la hacienda de Cochangasta como lugar rural.22 Extrapolando datos de padrones posteriores, es razonable suponer que no más de un tercio de los empadronados residían efectivamente en el casco urbano en $1767 .{ }^{23}$

La segunda aclaración -en la medida en que nos encontramos frente a un "padrón de autor"- concierne a quien (o mejor dicho a quiénes) recogieron y organizaron los datos. Ya nos referimos brevemente al juez comisionario Josep Antonio Baigorri de la Fuente. Cabe destacar que, aunque no era riojano sino cordobés, sus ancestros maternos lo ligaban a la ciudad y más precisamente a un personaje singular: don Pedro Nicolás de Brizuela, fundador -como vimos- del vínculo de Sañogasta. Baigorri descendía de la mayor de las hijas de Brizuela, que había seguido a su marido a la ciudad docta. Dos generaciones atrás, los antepasados cordobeses de Baigorri de la Fuente habían litigado la tenencia del mayorazgo en los estrados riojanos y en la Real Audiencia de Charcas. Aunque no tuvieron éxito y debieron resignar posiciones dentro de la elite, es muy probable que Baigorri de la Fuente mantuviera el trato con sus parientes riojanos, como era normal en una gobernación en la cual las redes familiares y sociales de los notables se solapaban. Señalemos, además, que este empadronamiento no sería la última misión de Baigorri en las tierras de sus ancestros: en 1769, nuestro hombre sería designado administrador de temporalidades de la jurisdicción y con ello recibiría la adhesión o el odio encarnizado de los vecinos que había clasificado dos años antes.

${ }^{21}$ E. Acevedo, “La Rioja hace dos siglos”, p.193.

22 AHPC, 2.37.21 (1768), f.28.

${ }^{23}$ Extrapolamos los datos del padrón del curato rectoral de 1795, examinado por Emiliano Endrek, "La población de La Rioja en 1795. Análisis de un padrón eclesiástico", en Revista de la Junta Provincia de Historia de Córdoba n. ${ }^{\circ} 11$, Córdoba, Junta Provincial de Historia de Córdoba, 1986, pp.179-23o. Es posible que, al igual que en Catamarca, las cuadras se dividieran en cuatro solares, subdivididos a su vez. Las chacras se extendían hacia el este, desde donde bajaba el agua que acequiada llegaba a las chacras y cuadras de los vecinos. 
Una vez arribado a La Rioja, nuestro personaje debió presentar sus credenciales y las órdenes del gobernador ante el cabildo, donde su pariente Bernardino Brizuela se desempeñaba como Protector General de los Naturales, un oficio clave de mediación en las visitas de indios tributarios (de las que Baigorri, como se recordará, también se encargó). Creemos que Bernardino jugó un papel decisivo en la confección del padrón del curato rectoral ya que, amén de su relación familiar con Baigorri, había sido nombrado notario de la Santa Cruzada. Aunque ignoramos cómo obtuvo este oficio, lo cierto es que los dos cargos lo situaban en posiciones centrales para producir la información solicitada a Baigorri. Nuestra hipótesis de trabajo es que el juez comisionario y el notario actuaron en conjunto en el momento del registro, siendo Brizuela el "informante clave" del primero, su pariente y hombre de referencia.

Brizuela era descendiente de la casa del mayorazgo y hemos reconocido su impecable desempeño como Protector de Naturales en otras ocasiones, acompañando la elaboración de padrones o ante la justicia local. ${ }^{24}$ Cabe destacar que el suyo no era un oficio de lustre; en rigor, Bernardino Brizuela jamás accedió a cargos que estuvieran en sintonía con el prestigio de su apellido. No es improbable que nuestro hombre fuera hijo natural de algún miembro de esta casa y que la sombra del señorío le permitiera moverse en el escenario de las familias connotadas, aunque ocupando espacios relativamente marginales. ${ }^{25}$ Es desde este particular lugar de liminaridad, socioeconómicamente en el borde de la elite pero ideológicamente

\footnotetext{
${ }^{24}$ Durante uno de estos episodios demostró tener un avezado conocimiento de las taxonomías socioétnicas de su tiempo, pudiendo clasificar a sus defendidas en relación a las mixturas que jalonaban sus respectivas genealogías. La etiqueta "pardo-zambas" da cuenta del resultado de uniones multiétnicas previas y del cálculo de las proporciones de las mismas. R. Boixadós y J. Farberman, Clasificaciones mestizas. Una aproximación”, pp.79-80.

${ }_{25}$ Posiblemente fuera sobrino de don Ignacio de Brizuela y Doria, señor del vínculo de Sañogasta, e hijo de don Bernardino de Brizuela y Doria. Un indicio de su dudosa condición (quizá era hijo natural o mestizo, o ambas cosas) es que no portaba el "de" antepuesto al apellido; firmaba como Bernardino Brizuela. Sus hijos varones llevaron el nombre de José (como su padre y hermano) y Juan Gregorio, siendo éste el nombre del primer señor del vínculo. El uso de nombres paradigmáticos dentro de una descendencia constituían marcas de pertenencia al evocar a los antepasados.
}

Dossier: Cuestionando las fuentes de archivos: padrones de población, familias y sociedades coloniales en Iberoamérica, ss. XVIII-XIX 
dentro de ella que, sospechamos, asesoró a Baigorri de la Fuente en la clasificación de los vecinos y habitantes de la ciudad.

Un segundo informante y socio de Baigorri debió ser el cura y vicario de la ciudad maestro don Miguel del Moral, quien a pesar de su escasa visibilidad fue citado para la elaboración en "consorcio" de testigos del "padrón universal". Sus antepasados provenían de la vecina ciudad de Catamarca y su padre Francisco estaba casado con doña Juliana de Luna, descendiente de los primeros conquistadores de La Rioja. Ocupó oficios capitulares, perfil que tuvo continuidad en el mayor de los hijos, siendo don Miguel destinado al sacerdocio. Según los registros parroquiales de la ciudad éste se había desempeñado como cura y vicario de Los Llanos pero desde noviembre de 1755 era cura rector propietario y vicario forense de la ciudad. Es decir que al momento de realizarse el censo, hacía 12 años que estaba al frente de la feligresía riojana y la conocía bien de cerca. Sus contactos, experiencia y buenos oficios le convirtieron tres años después de realizado el censo en tesorero de la Santa Cruzada. ${ }^{26}$

Hechas estas advertencias -y reconocida una casi triple autoría del relevamiento- vayamos al padrón de 1767. Como adelantamos, se trata de una fuente con una organización poco convencional, que consta de dos partes -una "razón general" y una "razón individual"- parcialmente superpuestas y en diálogo. En la "razón general", la unidad es la casa, categoría de clasificación que invocaba -además de una residencia- un colectivo que incluía al jefe de familia, su parentela y gentes de condición diversa "en su compañía". Reciprocidades y dependencias generaban entre los miembros de la casa jerarquías asimétricas, que resuenan con claridad en las categorías de "criados" y "agregados" y de manera más opaca en la de los numerosos "huérfanos" acogidos en las unidades domésticas. Por otra parte, como se verá luego, la jefatura de una casa se asociaba con una noción muy amplia de vecindad, en la que entraban todos los cabeza de familia varones. Quizás por ello, juez, cura y notario incluyeran en este universo a individuos "menos principales", jefes de casas pobres, apelando a un eufemismo que casi parece, con perdón del anacronismo, de

\footnotetext{
${ }^{26}$ Registros Parroquiales de la ciudad de La Rioja, Libro de Bautismos, ff.44 y siguientes. Como cura y vicario de la ciudad se desempeñó hasta 1784. Archivo del Arzobispado de Córdoba, gentileza Dra. Gloria Villafañe. L. Quarleri, “Elite local, burocracia y reformas borbónicas”, p.19o, se asume que el cura don Miguel del Moral era hermano de don Joaquín del Moral.
}

Dossier: Cuestionando las fuentes de archivos: padrones de población, familias y sociedades coloniales en Iberoamérica, ss. XVIII-XIX 
corrección política. Ello refuerza nuestra hipótesis acerca de una confección consensuada del padrón, que "protegió" a ciertos vecinos, portadores de apellidos prestigiosos y vinculados a la fundación de la ciudad pero que habían visto mermar su riqueza a través de las sucesivas generaciones.

La "razón individual" es el necesario complemento de la general. En ella, Baigorri recortó a una porción de los empadronados de aquella elite -en apariencia demasiado vasta- para clasificar más estrictamente a sus miembros según su notabilidad, recursos económicos y origen. Anticipemos desde ya que esta parte del padrón es individual sólo a medias porque nuestros censistas se limitaron a categorizar sociológicamente a los llamados -quizás demasiado ligeramente en la "razón general"- "vecinos principales".

En resumen, el padrón de 1767 encierra una manera de pensar la ciudad y la población urbana y periurbana, recortando y distinguiendo a los diversos segmentos que componían esta pequeña vecindad de provincia. Decodificar analíticamente este mapa social es el objetivo de este trabajo.

\section{Casas y vecinos "principales" y "menos principales"}

Al ser la casa la unidad privilegiada de la "razón general", Baigorri se ocupó de delimitarla nítidamente, sin omitir nunca el término en el encabezamiento de cada registro y separándolo de la siguiente por una línea. A la derecha de la cuadrícula, resumió el número de adultos adscriptos a la unidad, y a la izquierda, el de párvulos. El detalle de los miembros de cada casa sigue un orden jerárquico que reconoce escasas alteraciones: jefe o jefa de familia, sus hijos (y ocasionalmente otros parientes) y a continuación los criados, a veces también ellos organizados en familias. Hasta aquí, nada se aparta de los conteos habituales si no fuera porque la disposición de las casas sobre el papel no espeja la localización geográfica o el itinerario del censista sino jerarquías sociales, jurídicas y de género. En efecto, seis compartimientos organizan la información: en los primeros dos, se anota a los "vecinos principales" y "menos principales", en el tercero y el cuarto siguen las casas "principales" y "menos principales" lideradas por mujeres (en general, viudas o solteras),

Dossier: Cuestionando las fuentes de archivos: padrones de población, familias y sociedades coloniales en Iberoamérica, ss. XVIII-XIX 
en el quinto, las casas de los "clérigos presbíteros" y en el sexto y último los criados esclavos y libres de las órdenes religiosas (que aportarían una casa de pertenencia a aquellos dependientes).

Aunque la examinaremos con detalle en breve, cabe anticipar que la "razón individual" excluye a las mujeres y que, a diferencia del padrón masculino colectivo, demarca tres secciones en el universo de la vecindad "principal”. Así venimos a saber que no eran lo mismo los "sujetos principales", los "caballeros distinguidos" y el grupo algo más nutrido de la élite de tercera fila. Lamentablemente, sólo del primer segmento -de 15 personas - se realiza una auténtica "razón individual", describiéndose con minucia el patrimonio, origen y trayectoria de los personajes en los oficios de la república, mientras que para los otros dos agrupamientos se ofrece una descripción colectiva y escueta pero muy elocuente, detallando, si era el caso, los cargos ejercidos. ${ }^{27}$

En la "razón general" se contabilizaron 147 casas, más otras 5 a la cabeza de clérigos presbíteros. La población adulta de ambos sexos, según resume Baigorri en un breve informe, se contaba en 2.054 almas. Sin embargo, del empadronamiento surge un total de 1.954 individuos y tal será la cifra que tomaremos como referencia. Estos guarismos situaban a nuestro curato rectoral entre los más pequeños del Tucumán, no obstante se asentaran allí más del 20\% de los riojanos y algo más de un tercio de quienes eran tenidos por españoles. ${ }^{28}$ En efecto, el padrón del obispado de 1778 reporta a la ciudad de La Rioja -con 2.172 habitantes en aquel entoncesapenas por encima de Santiago del Estero (1776) y San Salvador de Jujuy (1707), manteniendo también el tercer lugar por la magnitud de su ruralidad después de

\footnotetext{
27 Por cierto, no debemos perder de vista el objeto del padrón y la función de la que había sido investido Baigorri de la Fuente. Como juez de los padrones universales de la Santa Cruzada, nuestro hombre debía asegurarse de que la bula fuera pagada. Sabía por experiencia que los riojanos eran huesos duros de roer y que apenas dos españoles habían cumplido el año anterior. Que los españoles -incluidos los más ricos- no tomaran la bula era considerada una falta grave y el padrón, además de controlar el cobro, ponía en evidencia las pasadas omisiones.

${ }^{28}$ Los criados libres y esclavos de la Compañía de Jesús -probablemente numerosos- no fueron contabilizados en aquel crítico de año de 1767, por la negativa del responsable a entregar la nómina.
}

Dossier: Cuestionando las fuentes de archivos: padrones de población, familias y sociedades coloniales en Iberoamérica, ss. XVIII-XIX 
las citadas cabeceras (con un 12,5 y 11.5\% respectivamente de población "urbana”). 29

Ahora bien, más que la exactitud de los datos numéricos del censo, nos interesa en este artículo explorar la mirada del censista y de su informante. En este sentido, lo primero a tener en cuenta en la descripción es la amplitud atribuida a la vecindad, que involucraba a la totalidad de los jefes de familia fueran éstos "principales" o "menos principales". Aunque más adelante analizaremos los alcances de esta vecindad, es llamativo el peso que tenía para estos actores el estar a la cabeza de una casa -o sea, de no residir con otra persona- y en las connotaciones señoriales del término estructurante del registro. Término que, por otra parte, se empleó indistintamente para las casas de mujeres y de vecinos "menos principales". Por otro lado, también amerita una reflexión el peso simbólico de ciertos apellidos tradicionales asociados a los años de la conquista. Ya dijimos que algunos descendientes ya lejanos de aquellos beneméritos del siglo Xvı habían perdido con los años no pocos de los atributos que hacían a su calidad originaria; sin embargo, Baigorri (o más bien Brizuela y Del Moral, soplándole al oído) encontró el modo de rescatarlos, aunque más no fuera sobre el papel. La primera división de los jefes de familia es la que reproducimos en la tabla 1 (para simplificar, incluimos a los clérigos presbíteros entre los "principales").

Tabla 1: jefes de familia más y menos principales

\begin{tabular}{||l|c|c|c||}
\hline & "Principales" & "Menos principales" & Total \\
\hline Jefe varón & 55 & 43 & 98 \\
\hline Jefe mujer & 23 & 31 & 54 \\
\hline Total & 78 & 74 & 152 \\
\hline
\end{tabular}

${ }^{29}$ Los datos del padrón de 1778 fueron publicados por Antonio Larrouy, Documentos del Archivo de Indias para la historia del Tucumán. Siglo XVIII, tomo II, Tolosa, 1927, s/p. Un análisis reciente de este documento y materiales censales posteriores, en Raúl Fradkin, "Población y sociedad", en Jorge Gelman (coord.), Argentina. Crisis imperial e independencia. 1808-1830, Lima, Taurus, 2011, pp.193-242. Hemos entrecomillado el adjetivo "urbano" dado el carácter mixto de los curatos rectorales.

Dossier: Cuestionando las fuentes de archivos: padrones de población, familias y sociedades coloniales en Iberoamérica, ss. XVIII-XIX 
Que en la primera descripción de un grupo supuestamente exclusivo los jefes de familia "principales" superen a los "menos principales" parece por sí mismo un dato anómalo. ¿Qué clase de élite era ésta en la que -según la conceptualización local- los "principales" superaban en número a quienes lo eran menos?

Comencemos por buscar una respuesta a partir de los mismos datos que proporciona la fuente. Cabe destacar en este sentido que ciertos atributos alcanzaban a los 78 jefes/as "principales", justificando su agrupamiento y distinción social. Previsiblemente, la totalidad de los "principales" fue distinguida con el don (o con el "doña", en el caso de las "señoras principales", viudas en su mayoría) y, con una solitaria excepción, alojaban criados (en número variable, como se verá) en sus casas. ${ }^{30}$ En cambio, entre los vecinos "menos principales" el panorama resulta más matizado y las generalizaciones se vuelven más inseguras. De manera evidente, el mismo Baigorri de la Fuente debió aceptar las indicaciones del notario y el cura para concederles los primeros lugares entre los "menos principales" a un grupo de personas de ambigua clasificación y que a todas luces requerían una posición consensuada. De todos modos, las tendencias generales se mantienen bastante nítidas: ausencia de criados (aunque con cinco salvedades), virtual desaparición del "don" (que registra cuatro excepciones o dudas clasificatorias) y registro entre los jefes de familia varones "menos notables" de un buen tercio de "indios", "mestizos" y "pardos".

Por otro lado, si examinamos el número de individuos que conformaban las familias "principales" y "menos principales" -dejando de lado los criados, que ameritan un análisis aparte- en su distribución, el panorama se revela algo más equilibrado. Así se aprecia en la tabla 2.

Lo dicho: si a los jefes de familia sumamos los individuos identificados como sus parientes, el universo de los "menos principales" trepa al 60\%. En estos hogares, los grupos de parentesco tendían a ser mayores y el número de individuos por casa no era compensado por agregados extraparentales. Podemos suponer que, de alguna manera, este sector se encontraba en una situación intermedia entre la de

\footnotetext{
30 No consideramos aquí un segundo caso en el que no hay criados pero sí un "huérfano" no connotado con el "don" que reside en la casa del vecino junto a su familia. Entendemos que se trata de una familia de criados no demasiado encubierta.
}

Dossier: Cuestionando las fuentes de archivos: padrones de población, familias y sociedades coloniales en Iberoamérica, ss. XVIII-XIX 
los "principales" y la de los criados, esclavos o libres, que les servían. Aunque Baigorri de la Fuente no se molestó en hacer una "razón individual" de este peculiar grupo de vecinos, no dejó de delimitar sus fronteras sociales. "Lo restante de dhos vecinos de esta ciudad", escribió el juez comisionario, se caracterizaba por su "inaveriguable nacimiento, los que se mantienen con su trabajo personal unos, y otros con algunas mulas y caballos que tienen". La descripción es sucinta pero transparente: el origen social dudoso y la necesidad de vivir de sus manos -así como la imposibilidad generalizada de acoger dependientes que la "razón general" espeja- caracterizaban a la "vecindad" pobre y sin prestigio.

Tabla 2: "Principales" y "menos principales". Individuos sin criados

\begin{tabular}{|l|c|c|c|}
\hline & "Principales" & "Menos principales" & Total \\
\hline Jefe varón & 292 & 357 & 649 \\
\hline Jefe mujer & 124 & 277 & 401 \\
\hline Total & 416 & 634 & 1040 \\
\hline
\end{tabular}

Si los "principales" y "menos principales" lideraban las casas, tocaba a los criados ocupar el último escalón en la estima social. Los había libres y esclavos, pero la "razón general" sólo especifica el status jurídico de los afincados en los conventos de Santo Domingo, San Francisco y La Merced. Siguiendo los registros del padrón, los criados alcanzaban el $46 \%$ de la población de la ciudad, imprimiéndole cierta configuración señorial a la sociedad riojana, no obstante su ancha y engañosa vecindad. En la tabla 3 figura la distribución de los dependientes de las casas: 
Tabla 3: criados y casas

\begin{tabular}{||l|c|c|c|}
\hline \multicolumn{1}{|c|}{ Casas } & Adultos & Párvulos & Total \\
\hline "Principales" Con jefe varón & 330 & 119 & 430 \\
\hline "Principales" Con jefe mujer & 142 & 37 & 179 \\
\hline "Menos principales" (ambos sexos) & 23 & 5 & 28 \\
\hline Ordenes religiosas (sólo libres) & 79 & 35 & 114 \\
\hline Ordenes religiosas (sólo esclavos) & 98 & 36 & 134 \\
\hline Total & 672 & 232 & 904 \\
\hline \hline
\end{tabular}

Como puede observarse, el 67\% de los criados se encontraban en la compañía de los señores y señoras "principales" (y en casi idéntica proporción), mientras que las órdenes religiosas -recordemos que no figuran aquí los jesuitas- concentraban el $27 \%$. En contraste, muy pocos entre los "menos principales" acogían criados, lo que marca una diferencia significativa con los padrones de Los Llanos que hemos trabajado en otra parte. ${ }^{31}$ La "razón individual" señala que también los señores "principales" tenían esclavos -y algunos de ellos hasta 30- probablemente repartidos entre las propiedades urbanas y rurales, y empadronados en la "razón general" sin especificación de status jurídico. Como sea, queda claro que un requisito tácito de la "vecindad" consistía en alojar en la casa a un nutrido séquito. De hecho, dejando de lado a las órdenes religiosas, un tercio de los dependientes de la ciudad era acogido en 15 casas y sabemos por padrones posteriores que el acceso a

${ }^{31}$ En el caso de Los Llanos, como en otros, la recepción de dependientes puede vincularse con estrategias de solidaridad campesina. De hecho, recibían agregados -aunque en menor cantidadunidades domésticas lideradas por jefes mulatos y mestizos. Ver R. Boixadós y J. Farberman, "Oprimidos de muchos vecinos" y de las mismas autoras "Propietarios, agregados y 'Pobres de Jesucristo'. Tierra y sociedad en Los Llanos riojanos en el siglo XVIII", en Historia Agraria n. ${ }^{\circ} 54$, Murcia, Universidad de Murcia, 2011, pp.41-70.

Dossier: Cuestionando las fuentes de archivos: padrones de población, familias y sociedades coloniales en Iberoamérica, ss. XVIII-XIX 
los esclavos se amplió luego de la expulsión de los ignacianos y de la venta de su patrimonio. 32

Como es sabido, la presencia de esclavos en la jurisdicción suele asociarse al reemplazo de la declinante población indígena encomendada. Sin embargo, las últimas guerras calchaquíes y las campañas a la frontera del Chaco facilitaron a través del sistema de composiciones un acceso alternativo a la mano de obra. Desde 1666 en adelante se repartieron encomiendas de nativos desnaturalizados que fueron instalados en las propiedades citadinas de sus "amos", soldados y capitanes de las campañas de guerra. Estos repartimientos reunían a pocas personas y familias y se fueron multiplicando con las expediciones oficiales realizadas al Chaco desde 1673, perdurando durante el siglo XVIII. Aunque a fines del siglo XVII algunas de estas encomiendas se encontraran en "cabeza de la corona", los dueños de las tierras siguieron beneficiándose de sus indios, pagando el tributo correspondiente a los administradores. Así pues, estas familias para todo servicio -que el padrón de 1767 releva entre los "criados"- evocan una relación de proximidad y dependencia muy estrecha con los dueños de la casa en la que habían nacido y crecido. ${ }^{33}$

\footnotetext{
32 Es una pena que el padrón de 1767 no diferencie a los criados esclavos alojados en las casas particulares (sólo nos informa que los 15 "principalísimos" concentraban unos 90) ya que, a la luz de conteos posteriores, la proporción de población esclava en La Rioja resulta muy llamativa para la escala de la jurisdicción y poco en sintonía con la pobreza que los vecinos no se cansaban de proclamar. En efecto, siguiendo el padrón de 1778, La Rioja ocupaba el tercer lugar -después de Córdoba y de Salta- en cuanto al número de esclavos registrados (1.199) y el segundo -después de Córdoba- respecto al porcentaje de población esclava sobre la total (12,3\%). Si nos limitamos al curato rectoral, la situación es más extrema: en la Rioja los esclavos conformaban 37,7\% de la población, superando al resto de las jurisdicciones, aún a Córdoba (31\%). En 1795, los esclavos del curato rectoral eran casi el 45\%, lo que no deja de ser asombroso. Según analiza Guzmán, la relación de masculinidad entre los esclavos era relativamente baja (82\%) y eran comunes las familias de mujeres esclavas casados con libres, que transmitían su condición a la descendencia. Sin duda, la expulsión de los jesuitas amplió el acceso de los vecinos a la población esclava y, como muestra Quarleri, en La Rioja no pocos accedieron a "precio de saldo". De todos modos, el problema de investigación sigue pendiente y nuestro padrón no proporciona demasiadas pistas para resolverlo. Ver M. F. Guzmán, "Familias de los esclavos" pp.225-242 y L. Quarleri, "Elite local, burocracia y reformas borbónicas", pp.177-209.
}

${ }^{33}$ La presencia de estos desnaturalizados en la ciudad ya es importante en la visita realizada en 1693 por el oidor de la Audiencia de Charcas Antonio Martínez Luján de Vargas. Ver Roxana Boixadós, "La visita de Luján de Vargas a las encomiendas riojanas (1693): comentarios, notas y lecturas

Dossier: Cuestionando las fuentes de archivos: padrones de población, familias y sociedades coloniales en Iberoamérica, ss. XVIII-XIX 


\section{Los contornos de una extendida vecindad}

Acabamos de comprobar que el tamaño del grupo dependiente que servía a los dueños de la casa era determinante para visibilizar la notabilidad social. Sin embargo, también lo eran otros atributos que sólo el conocimiento del contexto y un examen más exhaustivo del padrón permiten dilucidar. Justamente, la "razón general" hace explícita, a través del orden de registro de las casas, una representación de las jerarquías sociales según criterios acordados entre el juez comisionario, el cura y el notario. Proponemos a continuación una lectura de las "casas sobre el papel" guiada por la fuente, con el fin de comprender la lógica que sostuvo una clasificación social destinada a trascender los límites de la pequeña ciudad para mostrarse así a otros ojos. Leyendo el padrón como si fuera un mapa, es posible descubrir un ordenamiento tripartito basado en el prestigio social: la cúspide, el mando político y el grueso de los notables integrado por patricios y foráneos criollos y peninsulares.

En la cúspide fue ubicada una única casa, la del general Don Juan de Herrera y Paz, añoso patriarca descendiente de los conquistadores "por los cuatro abolengos", encomendero y cabeza de un hogar en el que vivía junto a su esposa, dos huérfanos y nada menos que 28 criados. Don Juan representa así el vértice máximo de prestigio, esposo de una nieta de quien fuera el riojano más ilustre, don Juan Gregorio Bazán de Pedraza y Texeda, criollo distinguido por el Rey con el nombramiento de gobernador del Paraguay.

La franja correspondiente al mando político de la comunidad incluye a los miembros del cabildo del año 1767. Las casas 2 a 8, en efecto, enlistan a los dos alcaldes (de primer y segundo voto), al alférez real, al procurador de la ciudad, a los dos alcaldes de la Santa Hermandad y al alcalde mayor de aguas, cada uno con sus respectivos parientes y criados. El prestigio derivado de la condición capitular no sorprende, pero cabe notar las diferencias con la composición del cabildo del siglo anterior, cuando las figuras predominantes eran las de los regidores, oficio adqui-

posibles”, en Roxana Boixadós y Carlos Zanolli, La visita de Luján de Vargas a las encomiendas de La Rioja y Jujuy (1693-1694). Estudios preliminares y fuentes, Buenos Aires, Universidad Nacional de Quilmes, 2003, pp.21-40.

Dossier: Cuestionando las fuentes de archivos: padrones de población, familias y sociedades coloniales en Iberoamérica, ss. XVIII-XIX 
rido por remate y transferible a la descendencia desde el cual se digitaba la elección de los alcaldes año a año. Ahora las alcaldías de la Santa Hermandad habían ganado valor, lo mismo que la de Aguas, oficio que solían ocupar en el pasado miembros de segundo o tercer rango. ${ }^{34} \mathrm{El}$ alférez real, en cambio, parece haber sostenido su prestigio como representante del rey, portador de sus insignias y del estandarte real. 35

En 1767 las alcaldías estaban en manos de criollos con apellidos ilustres (uno foráneo y otro local) mientras que los oficios de alférez real y de procurador de la ciudad recaían en jóvenes peninsulares casados con mujeres de familias prestigiosas (ambas Villafañe). De nuevo, las alcaldías mayores de la Santa Hermandad estaban ocupadas por criollos riojanos, uno de ellos hermano del cura vicario de la ciudad. Finalmente, el Alcalde Mayor de Aguas era un criollo santiagueño de antigua prosapia (Argañaráz y Murgía), esposo de una dama descendiente de un gobernador del Tucumán. Esta distribución de cargos entre antiguos y nuevos pobladores entramados a partir del parentesco y entre representantes de familias de mayor prestigio refleja una búsqueda de equilibrio de poder, tributaria de la antigua concordia de 1708 a la que nos referimos antes. ${ }^{36}$ Desde entonces, las familias "principales" se habían abocado al arte casi ajedrecístico de ubicar personas en lugares y espacios de poder que respondieran a sus intereses. Foráneos y peninsulares se integraban a esta lógica a través de alianzas matrimoniales que los posicionaban en un cierto espacio en relación a la familia de recepción y al resto de la elite.

\footnotetext{
${ }^{34}$ En 1708, don Alonso Moreno Gordillo declaraba que "el cabildo me eligió como alcalde de aguas y siempre tuvo el oficio gente baja así sintió por agravio la elección”. AHPC, expedientes del Crimen, Juzgado capitular, leg.2, exp.5. La nominación del oficio varió del Alcalde de Aguas a Alcalde Mayor de Agua.

35 Estos cambios se relacionan con el remate de cargos "nuevos" para beneficiar a la real Hacienda. Así, mientras que los alcaldes de la santa hermandad eran elegidos anualmente por los miembros del cabildo, el Alcalde Provincial de la Santa Hermandad se adquiría por remate e integraba el cuerpo capitular principal (con derecho a voto desde 1631). Lo mismo debió suceder con el alcalde de Aguas, cargo anual electivo reemplazado por el Alcalde Mayor de Aguas. Estos cargos perpetuos eran de mayor prestigio que los electivos. Ricardo Zorraquín Becú, Los cabildos argentinos, Córdoba, Imprenta de la Universidad, 1956.

${ }^{36}$ R. Boixadós, “Asuntos de familia, cuestiones de poder”, pp.147-171.
}

Dossier: Cuestionando las fuentes de archivos: padrones de población, familias y sociedades coloniales en Iberoamérica, ss. XVIII-XIX 
La tercera parte del registro de los vecinos "principales" comprende las casas de los "patricios", "naturales de los Reynos de España" y foráneos, todos igualados en tratamiento. Los primeros formaban parte del universo amplio pero con contornos bien delineados de familias de ascendencia conquistadora, nacidos en La Rioja. Están aquí los antiguos apellidos, algunos asociados a grandes casas y otros a familias con menos protagonismo y recursos pero igualmente ilustres. Algunos de estos vecinos eran encomenderos ("feudatarios") o lo habían sido sus mayores; otros ocupaban cargos de menor rango en el cabildo (como el de Protector de Naturales). Peninsulares y foráneos -de las ciudades de Córdoba, San Juan, Tucumán o del Paraguay- estaban integrados a la vecindad a través del matrimonio y algunos también disfrutaban de oficios de menor preeminencia que los capitulares (como Alguacil Mayor del Santo Oficio, Teniente de Correos, Mayordomo de la Iglesia Matriz). Así es que entre la casa 9 y la 46 fueron inscriptos los demás "principales", todos ellos precedidos por el "don". Dentro de este conjunto de "principales" reconocemos además los entornos de los informantes del padrón: la casa 7 corresponde a don Joaquín del Moral (alcalde de la Santa Hermandad), que vivía con sus padres, su esposa y una hija casada con un nieto, además de una hermana, un cuñado, cinco sobrinos y 22 criados entre adultos y párvulos, mientras que la casa 15 le correspondía a don Bernardino Brizuela, registrado con su esposa y siete hijos (uno de ellos casado y con hijo), grupo familiar atendido por solamente dos criados. ${ }^{37}$

Las últimas casas del registro de vecinos "principales" ofrecen un muestrario de jefes de familia cuya ascendencia, calidad y prestigio no resulta sencillo reconocer. En este sentido, detectamos ciertas lagunas o imprecisiones significativas, que seguramente ocultan datos que no querían ser expuestos. En líneas generales, es destacable la disminución del número de criados por unidad a partir de la casa 26 y la inclusión de ciertos miembros de condición ilegítima. Era éste el caso de la casa de don Ignacio de Agüero, quien moraba con su esposa, sus cinco hijos y un "hijo bastardo" cuya identidad se oculta, lo mismo que la de su mujer. También se sumaba a este hogar la anónima "cuñada del referido bastardo" y 14 criados. Aunque

\footnotetext{
37 Comparando ambas casas se advierte que la de los Del Moral convivían tres familias nucleares en una misma vivienda además de un importante número de criados, atribuible tal vez a la presencia de solo dos generaciones en suelo riojano, mientras que el notario -cuya familia estaba en La Rioja desde 1640- tenía su casa -al igual que su hermano- aunque la asistían pocos criados, indicios de una posición económica con ciertas limitaciones.
}

Dossier: Cuestionando las fuentes de archivos: padrones de población, familias y sociedades coloniales en Iberoamérica, ss. XVIII-XIX 
los censistas silenciaran el nombre del bastardo, no hay dudas acerca de su integración al grupo familiar, bajo cuyo amparo formaba el propio. ${ }^{38}$ Otro ejemplo en el mismo sentido es el de la casa de don Andrés Ocampo Isfrán, natural del Paraguay, teniente de oficiales reales e hijo natural de uno de los yernos del ilustre don Juan Gregorio Bazán de Pedraza y Texeda. Ocampo había crecido en La Rioja y fue sumado a la extensa parentela política de su padre. Ya mayor, se desempeñó como Protector de Naturales. Casado con una riojana de antigua prosapia (Mercado), vivía con sus cinco hijos y 12 criados. La inclusión de estos dos ilegítimos entre los "principales" connota la importancia de la filiación como criterio de adscripción, expresado a través del apellido, y sobre todo del vínculo socialmente reconocido a pesar de la condición de nacimiento.

Nuestro tercer ejemplo, el de don Pascual Quintero, ilustra la ubicación en la zona liminar entre los "principales" y los "menos principales". Quintero vivía en su casa con su mujer, nueve hijos y seis criados, además de una hija casada con su prole. Entendemos que este individuo figuraba entre los "principales" sólo por su condición de "vecino encomendero" ya que, de hecho, no se lo consideró "patricio" vistos sus orígenes bajos y la proximidad con sectores indígenas y mestizos. Por lo que sabemos, los antepasados de Quintero se habían instalado en la ciudad hacia fines del siglo XVII, cuando les fue asignada una encomienda como premio por servicios militares. Hacia fines del Setecientos, mantenían descendientes en un pueblo de reducción y un homónimo -Pascual Quintero- fue registrado en 1795 como "indio" a pesar de su identificación entre las más importantes fortunas ganaderas de Los Llanos. ${ }^{39}$

Por fin, la última casa del listado de "principales" corresponde a una pareja de apellidos de antigua raigambre (Almonacid y Luna), que vivían con dos hijos

\footnotetext{
${ }^{38}$ Sabemos de muchos otros hijos naturales o bastardos que componían la periferia de estas familias de elite, en cuyo seno se movían cumpliendo funciones bastante específicas. Roxana Boixadós, "No ha tenido hijo que más se le parezca así en la cara como en su buen proceder. Una aproximación al problema del mestizaje y la bastardía en La Rioja colonial”, en Memoria Americana, Cuadernos de Etnohistoria n. ${ }^{\circ} 13$, Buenos Aires, Facultad de Filosofía y Letras, Universidad de Buenos Aires, 2005, pp.83-115.

${ }^{39}$ R. Boixadós y J. Farberman, “Clasificaciones mestizas”, p.109
} 
pequeños y dos criados. Era ésta una familia joven, de modesta condición a pesar del apellido honroso, otro ejemplo del inexorable desgranamiento de la descendencia que acompañaba la distribución de un patrimonio arduo de recuperar desde posiciones periféricas.

Hasta aquí, los llamados "vecinos principales", con sus notables inequívocos y sus personajes ambiguos. ¿Qué ocurría con los "menos principales"? La expresión -como se demostrará- resulta menos elocuente de lo que parece. Con precedencia, expusimos algunas generalidades que definían al grupo - ausencia del "don", omisión del nombre del cónyuge, presencia de pardos, indios y mestizos entre los jefes de familia-. Lo que podemos agregar ahora es que el padrón no oculta tal heterogeneidad, manteniendo un orden jerárquico y, una vez más, incluyendo casos limítrofes y ambiguos que expresan dudas clasificatorias y tal vez la necesidad de consensuar la clasificación entre Baigorri, Brizuela y Del Moral.

Veamos: las primeras 9 casas pertenecen a sujetos de apellido ilustre, como la de don Nicolás Barrios, viudo anotado como "patricio" (sospechamos que se trataba del cuñado del notario Brizuela, lo que explicaría su posición relativamente honrosa). Tres personas de apellido Moreno - seguramente descendientes de la familia Moreno Maldonado, antiguos encomenderos que habían perdido recursos y notabilidad ya a comienzos del siglo XVIII- continuaban el listado pero de los tres hermanos sólo uno fue registrado como "patricio". El dato permite entrever que los otros dos no eran hijos legítimos y, de hecho, fuentes posteriores permiten corroborarlo para Francisco Moreno. ${ }^{40}$ Sin embargo, a contramano de la mayor parte de los vecinos "menos principales", los tres Moreno poseían criados (entre seis y diez por familia), marcas de adscripción al sector más alto en el que no fueron reconocidos.

Las siguientes casas -10 a 20- estaban presididas por jefes de familia indios, pardos y mestizos, inscriptos con sus mujeres e hijos. Salvo en dos casos, los apelli-

\footnotetext{
${ }^{40}$ Según las afirmaciones del peninsular don Juan Lucas de La Colina, “[...] su esfera es bien baja, su nacimiento es ilegítimo y adúlteros sus precedentes, partidas todas que acompañado a su soberbia le hacen bien odiado en esta ciudad [...]"; la expresión corresponde a un contexto de disputas por la administración y acceso a los bienes de los jesuitas expulsados. Citado en L. Quarleri, "Elite local, burocracia y reformas borbónicas”, p.194. Los vínculos de parentesco entre estos Moreno se deducen de la información de los Archivos Parroquiales de La Rioja.
}

Dossier: Cuestionando las fuentes de archivos: padrones de población, familias y sociedades coloniales en Iberoamérica, ss. XVIII-XIX 
dos pertenecen al grupo de los más antiguos, portados ahora por descendientes mestizos o dependientes, así nominados por ser libres de condición. En este grupo se destaca don Joseph Villafañe, apellido de los más notables, casado con una mestiza con quien posiblemente compartía el mismo origen. Le siguen una veintena de hogares de españoles, salpicados por tres casas presididas por un pardo y dos indios, entre las que se desdibujan, y cierra el apartado la casa de don Ignacio de Herrera, su esposa e hijos, todos distinguidos con el "don". Su ubicación marginal en el último lugar de esta sección nos lleva asociarlo con don Juan de Herrera y Paz, la cúspide de esta singular pirámide de jerarquías. ¿̇Sería acaso un hijo -o nieto- natural o ilegítimo que no podía quedar del todo excluido de esta clasificación de vecinos?. ${ }^{41}$ Es probable y ello explicaría una inscripción entre los "menos principales" decidida a último momento.

Ya sabemos que el recorrido de la "razón general" proseguía con la enumeración de las señoras "principales" y de las "menos principales" y que, mientras las primeras fueron inscriptas en 22 casas, las segundas lo fueron en 30. Empero, las pistas son más escasas sobre las mujeres, en la medida en que no se hizo una "razón individual" de ellas que permita contrastar la información. Podemos generalizar que la mayoría de las "señoras principales" -todas doñas- eran viudas o solteras y vivían en compañía de alguno de sus hijos, de hermanas o cuñadas y de un numeroso séquito de criados (doña Francisca Dávila, cuenta con 21 criados), que todos los apellidos que aparecen en el registro pertenecen a los abolengos locales o de las ciudades vecinas y que doce tenían las "conveniencias" adecuadas para pagar la Bula de la Santa Cruzada. De estos pocos datos, se infiere que la mitad de las señoras contaban con bienes propios aunque la fuente no detalla cuáles eran ni qué alcances tenían. También descubrimos que, paradójicamente, algunas de estas señoras eran casadas, no obstante fueran ellas quienes revistaran como jefas de familia en el padrón. Los esposos -reportados en todos los casos en la "razón individual"pertenecían a la tercera fila de los vecinos "principales", indicando posiblemente uniones homogámicas entre miembros de segundas líneas de prestigio.

\footnotetext{
41 Otros dos jefes de familia "principales" pertenecen al grupo de ascendencia de los Herrera -don Francisco, Maestre de Campo y don Joseph, capitán- situados en las casas 13 y 28 respectivamente, todos ellos descendientes de don Alonso de Herrera y Guzmán.
}

Dossier: Cuestionando las fuentes de archivos: padrones de población, familias y sociedades coloniales en Iberoamérica, ss. XVIII-XIX 
En cuanto a las casas de las señoras "menos principales", hallamos en el listado apellidos de prestigio junto a otros que evocan sectores de menor jerarquía, incluso de castas o mestizos, como Corso, Ruarte, Oliva, Torres. Mujeres sin apellido como "Micaela" registrada junto a su marido y sus hijos como jefa de hogar, o "María Sabina mujer del mulato Simón", integran un variado conjunto que cierra con dos casas peculiares que vale la pena detallar. La penúltima, presidida por la viuda Mariana Quintero (hija del ya referido encomendero don Pascual Quintero, ubicado en el último escaño de los "principales"), fue agregada con caligrafía apretada en una estrecha franja intermedia del texto. El menor de los hijos, Cándido quien sería un prolijo sacerdote del curato de Los Llanos- fue registrado apenas por encima de la línea de cierre; su padre era un Sotomayor con muy pocos caudales. La última, encabezada por Juan Salazar, esposo de doña Francisca Vega e inclusiva de los hijos de ambos, permite entrever un casamiento desigual ya que sólo la mujer fue anotada como "doña" (aunque posiblemente la casa perteneciera al marido).

\section{La sociedad riojana a través del padrón}

Si la "razón general" puede leerse como la autorrepresentación de una vecindad a partir del prestigio, la individual es una proyección anclada en los recursos económicos y por tanto de la capacidad de los empadronados para adquirir la bula. Por tal motivo, este segundo listado se superpone sólo parcialmente con el de los jefes de familia "principales": ciertos personajes figuran sólo en una de las dos razones, o bien no aparecen encabezando las casas de la "razón general". ${ }^{42}$ Como resultado, si en la "razón general" se contaban 55 jefes "más principales", en la individual fueron considerados 67 vecinos. De la misma manera, algunos personajes notables que figuran en la "razón general" -entre los cuales tres peninsulares y el notario Brizuela- fueron omitidos de la individual -sospechamos- por carecer u ocultar bienes propios.

42 Hay 22 individuos que, o bien fueron omitidos en la "razón general”, o están “ocultos" en ella. En efecto, son numerosos los apellidos no especificados de parientes de los jefes de familia. Por otra parte, en diez casos, la "razón individual" se ocupa de sujetos registrados como cuñados, yernos y aún como cónyuges de "señoras principales".

Dossier: Cuestionando las fuentes de archivos: padrones de población, familias y sociedades coloniales en Iberoamérica, ss. XVIII-XIX 
Anticipamos ya que en la "razón individual" se reconocen tres segmentos. El primero es el de los 15 individuos con datos completos, distinguidos con nitidez por capacidad económica, y secundariamente, reputación y poder político además de por ocupar sus miembros, sin excepción alguna, la jefatura de familia. ${ }^{43}$ De esta cúpula, nada menos que cinco vecinos eran peninsulares, cuatro de los cuales menores de 40 años. Aunque solamente en seis casos se especificó el capital que poseían -y que oscilaba entre 2.000 y 10.000 pesos- vale destacar que eran peninsulares los titulares de una y otra punta y que quien contaba con mayor caudal -don Juan Lucas de la Colina, entonces alcalde ordinario y mayordomo de la Iglesia Matriz-, orillaba apenas los 30 años. En efecto, un dato sobresaliente de este núcleo duro de la élite es su composición por grupos de edad y la correspondencia aproximada de éstos con los orígenes geográficos: mientras que de cuatro se especificó la "edad avanzada", cinco conformaban una cohorte intermedia de entre 40 y 60 años y nada menos que seis (entre los cuales cuatro peninsulares) eran jóvenes de entre 25 y "más de 30 años".

También es posible delinear sumariamente perfiles ocupacionales asociados al grupo de edad y a la procedencia. La "razón individual" identificó cuatro comerciantes, ocho propietarios de estancias de ganado y siete de viñas generalmente cercanas a la ciudad. Entre los más viejos, ganadería, actividad viñatera y comercio se registran como actividades separadas y entre los de mediana edad -entre los que no figura comerciante alguno- los estancieros y viñateros coincidían en las mismas cinco personas. Lo notable es que tres comerciantes (uno de los cuales también estanciero y viñatero) fueron señalados entre los "jóvenes", además de un vecino de actividad ignota y otro propietario de un mayorazgo en Galicia.

Por cierto, todos estos datos de la "razón individual" deben tomarse con pinzas. Aunque la pintura que se nos ofrece -muy esquemáticamente- es la de comerciantes /jóvenes/ peninsulares versus viñateros/ estancieros/ locales, otras fuentes permitirían matizarla un tanto. Además de los jóvenes radicados en fechas más

43 Todos ellos eran dueños de haciendas y viñas, propietarios de ganados y esclavos, poseían caudales de hasta 8000 pesos y algunos de ellos eran destacados comerciantes. En la nómina figuran los notables criollos como así mismo los peninsulares integrados a las familias de mayor prestigio y todos estaban -o habían estado- cumpliendo funciones de administración o gobierno.

Dossier: Cuestionando las fuentes de archivos: padrones de población, familias y sociedades coloniales en Iberoamérica, ss. XVIII-XIX 
cercanas al censo - Sedano, García Tagle, de la Colina y Gómez, el más joven de todos- había otros integrados a la élite riojana décadas atrás, como Camaño y Fernández de Córdoba. Unos y otros habían llegado con caudales propios a los que sumaron las dotes de sus mujeres que pronto hicieron rendir -económica y simbólicamente si éstas habían heredado también haciendas o mayorazgos- aprovechando las ventajas de su nacimiento en un contexto de cambio de la administración colonial. La capa más joven encontraría un nuevo impulso poco después del censo, que se expresaría la asunción roles de importancia en el gobierno local, articulando los intereses personales y familiares. ${ }^{44}$

Sin embargo, no todos los peninsulares se encontraban en la cúpula (de hecho varios figuran en la "razón general" ocultos entre los cuñados y los yernos del jefe de la casa y entre los "principales" de segunda y tercera fila de la "razón individual"), signo de que tales orígenes por sí solos no garantizaban ascensos automáticos ni carreras fulgurantes. Por otra parte, también los riojanos de primera fila mercadeaban, aunque la "razón individual" sólo lo explicite para las filas inferiores de la élite. Entendemos que los patrimonios de entre seis y ocho mil pesos -como los de Josep Carreño o Melchor Almonacid- no se acumulaban exclusivamente laboreando viñas y criando ganado, aunque los censistas hayan optado por silenciar en estos casos la actividad comercial.

A los 15 "principales" de la cúpula, les seguían en la "razón individual" 22 individuos, de los que se especificaba únicamente la edad y los cargos de la república ejercidos. Por lo menos diez de estos sujetos no ocupaban la jefatura de familia y figuraban en la "razón general" como yernos, cuñados y, en un caso, como esposo de una "señora principal". Según Baigorri, este grupo intermedio de "caballeros distinguidos de esta dha ciudad" poseía

\footnotetext{
${ }^{44}$ Son muchos los estudios generales y regionales que comprueban esta tendencia en el Tucumán; cfr. Ana María Lorandi, Poder central, poder local. Funcionarios borbónicos en el Tucumán colonial. Un estudio de antropología política, Buenos Aires, Ed. Prometeo, 2008; Gabriela Tío Vallejo, Antiguo Régimen y Liberalismo. Tucumán, 1770-1830, San Miguel de Tucumán, Universidad de Tucumán, 2001; Marcelo Marchionni, “Acceso y permanencia de las elites en el poder político local: El cabildo de salta a fines del periodo colonial”, en Cuadernos de la Facultad de Humanidades y Ciencias Sociales n. ${ }^{\circ} 13$, San Salvador de Jujuy, Universidad Nacional de Jujuy, 2000, pp.283-306, entre otros.
}

Dossier: Cuestionando las fuentes de archivos: padrones de población, familias y sociedades coloniales en Iberoamérica, ss. XVIII-XIX 
sus casas en esta república medianamente decentes, tienen sus viñas cortas, tienen sus guertas, sus algodonales, algunas mulas y caballos, tratan y contratan en géneros de los cuales producen dhas haciendas, los más de ellos han obtenido empleos públicos en esta y pueden obtenerlos todos en adelante ellos y sus hijos por ser nobles por los cuatro abolengos (negrillas nuestras)

Entendemos que la clave para pensar este grupo intermedio reside en el último atributo, la nobleza "por los cuatro abolengos", correspondiente aproximado de la categoría de "patricio" de la "razón general". Descendientes de beneméritos pero ya no tan ricos, estos sujetos estaban de todos modos facultados para ocupar los cargos políticos de la república (los “empleos públicos”). Es más: ser patricio era uno de sus requisitos para ejercerlos.

Por fin, el último segmento de la "razón individual" estaba compuesto por 30 individuos. De manera evidente, la clasificación en este grupo fue más flexible y tres de los sujetos registrados directamente no figuran en el padrón de las casas (o se hallan ocultos los hijos de viudos, yernos o cuñados sin apellido). ${ }^{45}$ Resulta también significativo que cuatro de ellos fueran anotados en la "razón general" a continuación de sus esposas (dos de las cuales "menos principales"...) y uno reportara entre los vecinos "menos principales" (portando, no obstante el "don"). Los restantes 18 individuos constan entre los vecinos "principales" de la "razón general". Según el censista, estos vecinos estos vecinos de tercera fila compartían

sus casas de ordinaria fábrica y homenaje correspondiente, los más de ellos tienen sus viñas cortas, sus algodonales y sus huertas e higueral y otros árboles frutales, asimismo siembran cantidades de maíz, muchos de ellos tienen mulas mansas y caballos con los que trajinan fletándolos y conduciendo a la de Córdoba los frutos y productos de sus viñas y chacaras. Los mas de ellos tienen uno u otro esclavo y los más se sirven de gente libre y personalmente.

Como podrá notarse, las actividades económicas indicadas para los tres grupos son siempre las mismas -actividad viñatera, ganadera y comercio- mientras que -al parecer- el segundo y el tercer grupo las desarrollaban en escalas semejan-

${ }^{45}$ Se trata de Pantaleón Ahumada, Hilario Cabrera y Josep Días de Loria.

Dossier: Cuestionando las fuentes de archivos: padrones de población, familias y sociedades coloniales en Iberoamérica, ss. XVIII-XIX 
tes, quizás de manera más diversificada (y obviamente más reducida) que los 15 de la cúpula. La diferencia más importante que acomunaba a los vecinos de la tercera fila es que muy pocos ocupaban o habían ocupado cargos capitulares. En compensación, varios de estos vecinos ostentaban rangos militares (capitanes, maestre de campo, sargentos). Sabemos por nuestros trabajos de investigación anteriores que de esta elite de tercera fila salieron los "señores" de Los Llanos, cuyos blasones tendrían mejores oportunidades de brillar en un espacio de poblamiento tardío. ${ }^{46}$ Este rasgo, que por supuesto no aparece en la caracterización de la "razón individual", podría apuntar a un conjunto de "segundones" - algunos de ellos bastardos- y colonizadores de zonas fronterizas. Fue en esta fila del borde de la élite donde el notario Brizuela anotó a su hijo y a su hermano (aunque, significativamente, se omitió a sí mismo).

En suma, al comparar los esquemas de jerarquías que resultan de analizar la "razón general" y la "razón individual" encontramos que los criterios del patriciado y el prestigio por un lado y el económico por el otro se articulaban parcialmente, dejando entrever distancias entre el modo de autorrepresentación de la vecindad local y las capacidades concretas de sostener un modo de vida acorde. Ese modo de vida -además de en el número de criados- se hacía visible también en la factura de las casas. Por eso la "razón individual" se ocupó también de describir la "decencia de la casa y su correspondiente homenaje" (menaje) de los miembros de la cúpula. Las viviendas de los 15 más ricos fueron calificadas como de "bella", "muy buena" "buena" y "razonable fábrica" aunque únicamente la de don Ignacio Villafañe y Tejeda fuera "de la mejor fábrica" y la de don Josep Carreño contuviera un "menaje superior" en sus habitaciones. En cualquier caso, queda claro que en comparación con las casas "medianamente decentes" del segundo grupo y las de "ordinaria fábri-

\footnotetext{
${ }^{46}$ Es el caso de varios miembros de las familias Peñaloza, Mercado, Galván, Quintero, Sotomayor y De la Vega, "señores" llanistas y élite de tercera fila de la ciudad. Ver R. Boixadós y J. Farberman, "Clasificaciones mestizas. Una aproximación a la diversidad étnica y social en Los Llanos riojanos. Siglo XVIII", pp.79-114, y "Propietarios, agregados y Pobres de Jesucristo'. Tierra y sociedad en Los Llanos riojanos en el siglo XVIII", pp.41-70.
}

Dossier: Cuestionando las fuentes de archivos: padrones de población, familias y sociedades coloniales en Iberoamérica, ss. XVIII-XIX 
ca" del tercero, las pertenecientes a los propietarios del primero se le antojaron señoriales al censista don Josep Baigorri de la Fuente. ${ }^{47}$

Llegados a este punto, es necesario regresar a la cuestión de la vecindad y revisar su aparente amplitud con la ayuda de la "razón individual". Ya se dijo antes que el censista y sus agentes llamaron vecinos a todos los jefes de familia, fueron estos "principales" o "menos principales". Entre los segundos- generalmente pobres y de "inaveriguable nacimiento"- participaban sujetos que portaban apellidos plebeyos (Torres, Vargas, Molina, Rivera, etc.) y otros que remitían a la hueste conquistadora (Moreno, Bazán, Villafañe, Quijano, Barrionuevo, Díaz, etc.) pero ni siquiera estos últimos calificaban en su totalidad como "españoles" en 1767. ¿Podría entenderse este gesto como deferencia hacia una población citadina que, enredada en sus parentescos múltiples, conformaba una trama demasiado apretada para excluir sin disimulos a sus dependientes demasiado próximos o a parientes con alguna mácula en su haber? Aunque así fuera, eran sin dudas muy pocos entre los "menos principales" los que arañaban la "decencia” y por eso se los identificó como un grupo subordinado. Jefatura de la propia casa, arraigo y por lo tanto identidad con la patria eran los atributos positivos de estos vecinos, que dibujaban los contornos de una vecindad en sentido muy laxo.

Sin embargo, la vecindad revestía también un sentido más estricto, con dos contenidos fundamentales que sólo concernían al sector que los censistas llamaron "principal": el componente social y el político. ${ }^{48} \mathrm{El}$ primero apunta a la forma en que esta sociedad se autorrepresentaba hacia afuera, sin esconder las jerarquías que organizaban y distanciaban por dentro a sus miembros. En este sentido, todos los "principales" del padrón -que seguían siendo numerosos- cumplían con este

\footnotetext{
${ }^{47}$ La descripción probablemente fuera exagerada ya que al fin de cuentas era interesada y apuntaba a demostrar que la mayoría se hallaba en condiciones de comprar la bula. Unos 20 después de este censo, en 1785, el gobernador Sobremonte se refería a nuestro lugar como a "pueblo pobre y corto" [...] la fábrica de las casas es miserable y la frugalidad con qe viven igual a la que he referido de las campañas de esta provincia”. Archivo General de la Nación, sala IX, 5-8-5.

48 Tamar Herzog, "La vecindad: entre condición, formal y negociación contínua. Reflexiones en torno de las categorías sociales y las redes personales", en Anuario IEHS n. ${ }^{\circ}{ }_{15}$, Universidad Nacional del Centro de la Provincia de Buenos Aires, Tandil, 2000, pp.127-128.
}

Dossier: Cuestionando las fuentes de archivos: padrones de población, familias y sociedades coloniales en Iberoamérica, ss. XVIII-XIX 
requisito. Incluso la tercera fila de la élite descripta en la "razón individual" -los pobres pero decentes- ingresaban por completo en esta clasificación y bien lo sabían. En segundo lugar, la vecindad tenía un alcance político que alcanzaba sólo a un grupo restringido en el que convergían el prestigio, la calidad y los recursos económicos. Era, en efecto, entre los sectores más altos y en las fracciones intermedias -los dos primeros segmentos de la "razón individual"- donde se recortaban los límites políticos de la vecindad, es decir los ámbitos de pertenencia de quienes estaban habilitados para ocupar cargos en el cabildo. Por este motivo, la distribución de los cargos de la república entre los personajes censados resulta bastante previsible: mientras que casi todos los hombres de la cúpula y dos tercios del círculo intermedio los habían desempeñado, menos de la cuarta parte de los notables de tercera fila los ejercían o habían ejercido en el pasado próximo. ${ }^{49}$

\section{Reflexiones finales}

A lo largo del siglo XVIII, la dinastía borbónica acrecentó sus demandas de información sobre muy variados temas, impulsando a través de sus burócratas y agentes la realización periódica de visitas, censos e informes. ${ }^{50}$ Incluso jurisdicciones tan periféricas como La Rioja recibieron la presencia de comisionarios que, como Baigorri de la Fuente, debían emprender la tarea de reconocer y clasificar a la vecindad. La misión requería de averiguaciones precisas, de la revisión de documentación local

\footnotetext{
49 Es interesante notar que todos los apellidos de raigambre local de los "principales" figuran en fuentes diversas formando parte del cuerpo capitular, tanto en los oficios más prestigiosos como en los menos. Esto significa que salvo los peninsulares y los criollos de otras jurisdicciones en 1767 todos tenían antepasados capitulares en La Rioja. Sin embargo, queda muy claro que entonces sólo los más prestigiosos y de mayor caudal tenían acceso al cabildo; el censista empero, les reconoció sus derechos, como ya fue citado: "los mas de ellos an obtenido oficios públicos en esta y pueden obtenerlo todos en adelante ellos y sus hijos por ser nobles por los cuatro abolengos" AHPC, 2, 37, 21 (1768), f.583.

50 Como se sabe las requisitorias fueron más frecuentes en el último cuarto del siglo XVIII. Ver Juan Marchena, "Su majestad quiere saber. Información oficial y reformismo borbónico: el mundo andino bajo la mirada de la ilustración", en Procesos, Revista Ecuatoriana de Historia n. ${ }^{\circ} 22$, Quito, Universidad Andina Simón Bolívar, 2005, pp.45-83.
}

Dossier: Cuestionando las fuentes de archivos: padrones de población, familias y sociedades coloniales en Iberoamérica, ss. XVIII-XIX 
preexistente y de la consulta a los representantes autorizados de la comunidad de vecinos notables, como del Moral y Brizuela. Entre el 15 de diciembre de 1766 y el 4 de marzo siguiente, durante tórridas jornadas del verano, se construyó coralmente el "padrón universal" del curato rectoral riojano que, como toda fuente de este tipo, descubre tanto como encubre información entre sus líneas. Ha sido nuestro objetivo reconstruir la imagen que quisieron proyectar sus autores y que requirió también de la minimización de ciertos datos para que pasaran desapercibidos.

Como autorrepresentación, el padrón traduce una figura piramidal, presidida por un grupo de familias reconocidas como "patricias" o "nobles", términos por completo inusuales en el resto de las ciudades de la gobernación, y que hablan por sí mismos del prestigio heredado como condición distintiva. El afán de connotar una ilustre superioridad de los vecinos de la ciudad a los funcionarios que leyeran el padrón los llevó a emplear las singulares categorías de "principales" y "menos principales", donde el ser "principal" resultaba una condición general que admitía alteraciones de grado en un conjunto de personas y familias. La misma dicotomía abarcaba el universo de las mujeres viudas y solteras, afectadas por el mismo desplazamiento descendente de la calidad. Ya vimos que entre los "menos" figuraban mestizos, pardos e indios (la mayoría de "inaveriguable nacimiento") y personas "manchadas" con la mácula de la ilegitimidad (o sus antepasados) algunos de los que no obstante fueron ubicados en los primeros lugares de la clasificación debido a la identidad de sus familias (y en un caso a sus caudales...).

El registro por casas sigue un orden de prestigio y casi podemos entrever su ubicación en el damero de la ciudad, en torno a una plaza y a un cabildo derruido con una iglesia matriz a medio terminar, donde los solares ubicados hacia el este eran los más favorecidos al recibir los primeros turnos de riego en sus chacras. Las casas de los "principales" reunían el mayor número de criados libres y esclavos cuya presencia proyectaba la condición señorial y el comensalismo con sus "amos". Ya que, mientras los esclavos podían eventualmente comprarse, los criados libres formaban parte de una herencia ancestral que evocaba la antigua institución de la encomienda, aún no del todo extinguida en la jurisdicción. En principio, los criados estaban asociados a las chacras y haciendas y a quienes fueran sus propietarios pero es probable que entraran dentro de los repartos "informales" de bienes entre los

Dossier: Cuestionando las fuentes de archivos: padrones de población, familias y sociedades coloniales en Iberoamérica, ss. XVIII-XIX 
herederos. De este modo, la menor presencia de criados en casas de los "principales" también alude a los procesos de pérdida de prestigio y caudal dentro de antiguas familias patricias.

Entre los de "arriba" y los de "abajo" -la mayoría de los "menos principales", los criados y esclavos- es posible identificar a un segmento que ocupaba los escalones más bajos de los "patricios" y que corresponde grosso modo a la tercera fila de la "razón individual". Este sector es interesante porque reúne a familias desplazadas de la primera línea de prestigio y que intentan recuperarlo engrosando sus caudales, y también a otras que ensayan con esfuerzo el desafío del ascenso social. Unos y otros tienen en común la búsqueda de mejorar sus condiciones de vida y como pequeños emprendedores han ido colonizando tierras en la región llanista donde comenzaba a despuntar los beneficios de la actividad ganadera. Algunos de ellos o sus familiares están presentes en el padrón de Los Llanos que el mismo Baigorri de la Fuente elaboró junto al cura párroco Dr. Nicolás Videla del Pino. Doña Rosa Gutiérrez por ejemplo, señora "principal” y viuda (de Jorge Vega) vivía en la ciudad con sus 9 hijos (solo uno menor) dos yernos y ningún criado. Sin embargo, el mismo grupo familiar fue empadronado en la estancia de Casangate, junto a varios agregados, una esclava y una pareja de españoles con sus hijos. La extensa familia mantenía doble residencia y no fueron los únicos. El menor de los hijos de doña Rosa llegaría a ser uno de los ganaderos más ricos de Los Llanos hacia fines del siglo XVIII.

Lo anterior nos devuelve al contexto de la realización de este padrón universal, que lamentablemente quedó inconcluso. Comentamos ya que unos pocos años antes, los miembros del cabildo habían elaborado un informe en el que reclamaban al rey los perjuicios que las medidas impositivas causaban a los vecinos, particularmente la alcabala, la sisa y el gravamen al aguardiente, ahogando un ya limitado comercio. Pero el programa reformista habría de favorecerlos justamente a partir de 1767, con la liquidación de los bienes de los jesuitas y en particular de los esclavos que la orden poseía, comprados a bajos precios y pagados a plazos por los "principales" bajo la administración de la Junta de Temporalidades. En el accionar de esta Junta se advierte el reposicionamiento de los peninsulares que, integrados a las redes patricias locales, aprovecharon la ventajosa coyuntura para enriquecerse y ganar cierta autonomía como agentes de administración borbónica. En las siguien-

Dossier: Cuestionando las fuentes de archivos: padrones de población, familias y sociedades coloniales en Iberoamérica, ss. XVIII-XIX 
tes décadas veremos a varios de los jóvenes peninsulares registrados en 1767 entre los señores "principales" (Gómez, González, Tagle, Sedano de la Torre) sacar partido de su rol de funcionarios en la administración estatal.

\section{Bibliografía}

\section{Fuentes primarias:}

Archivo Histórico de la Provincia de Córdoba (AHPC), Cajas de Gobierno,

Archivo General de la Nación, sala IX.

Vázquez de Espinosa, Antonio, Compendio y descripción de las Indias Occidentales, Washington, Smithsonian Miscellaneous Collection, 1948.

\section{Fuentes secundarias:}

Acevedo, Edberto, "La Rioja hace dos siglos", en Investigaciones y Ensayos n. ${ }^{\circ}$, Buenos Aires, Academia Nacional de la Historia, 1968, pp.191-213.

Aramendi, Bárbara, "El ramo de bulas de la Santa Cruzada en el Tucumán colonial”, en Diálogo Andino n. ${ }^{\circ} 33$, Universidad de Tarapacá, 2009, pp.5974 .

Bascary, Ana María, Familia y vida cotidiana. Tucumán a fines de la colonia, San Miguel de Tucumán, Facultad de Filosofía y Letras, Universidad de Tucumán, 1999.

Bazán, Armando Raúl, Historia de La Rioja, Buenos Aires, Plus Ultra, 1979.

Boixadós, Roxana, Tierra de hombres de cuatro abolengos. Parentesco y familia en La Rioja colonial. Tesis de Maestría inédita, Museo Nacional, Universidad Federal de Rio de Janeiro, 1996. 
Boixadós, Roxana, "Transmisión de bienes en familias de elite. Los mayorazgos de La Rioja colonial”, en Andes, Antropología e Historia n. ${ }^{\circ}$ 10, Salta, CEPIHA, 1999, pp.51-78

Boixadós, Roxana, "Cuñados no son parientes sino accidentes." Conflictos familiares en torno a la herencia de Cochangasta (La Rioja, siglo XVIII), en Anuario $\mathrm{n}^{0}{ }_{1}$, Córdoba, Centro de Estudios Históricos Prof. Carlos S.A. Segreti, 2001, pp.39-6o.

Boixadós, Roxana, "Familia, herencia e identidad. Las estrategias de reproducción de la elite en La Rioja colonial (gobernación del Tucumán, siglo XVII y principios del XVIII)", en Revista de Demografía Histórica vol.XIX, $\mathrm{n}^{\mathrm{O}}$ II, Zaragoza, ADEH, 2001, pp.147-181.

Boixadós, Roxana, "La visita de Luján de Vargas a las encomiendas riojanas (1693): comentarios, notas y lecturas posibles", en Roxana Boixadós y Carlos Zanolli, La visita de Luján de Vargas a las encomiendas de La Rioja y Jujuy (1693-1694). Estudios preliminares y fuentes. Bernal, Universidad Nacional de Quilmes, 2003, pp.21-40.

Boixadós, Roxana, "Asuntos de familia, cuestiones de poder. La 'concordia' en el cabildo de La Rioja (gobernación del Tucumán) en 1708" in Colonial Latin American Historical Review vol.2, n. ${ }^{\circ} 13$, Albuquerque, Spanish Colonial Research Center, 2005, pp.147-171.

Boixadós, Roxana, "No ha tenido que más se le parezca así en la cara como en su buen proceder. Una aproximación al problema del mestizaje y la bastardía en La Rioja colonial", en Memoria Americana, Cuadernos de Etnohistoria n. ${ }^{\circ}$ 13, Buenos Aires, Facultad de Filosofía y Letras, Universidad de Buenos Aires, 2005, pp.83-115.

Boixadós, Roxana y Farberman, Judith, "Oprimidos de muchos vecinos en el paraje de nuestra habitación”. Tierra, casa y familia en Los Llanos de La Rioja colonial”, en Boletín del Instituto Ravignani n. ${ }^{\circ} 31$, Buenos Aires, Facultad de Filosofía y Letras Universidad de Buenos Aires, 2009, pp.11-31.

Boixadós, Roxana y Farberman, Judith, "Clasificaciones mestizas. Una aproximación a la diversidad étnica y social en Los Llanos riojanos. Siglo XVIII", en

Dossier: Cuestionando las fuentes de archivos: padrones de población, familias y sociedades coloniales en Iberoamérica, ss. XVIII-XIX 
Judith Farberman y Silvia Ratto (coords.), Historias mestizas en el Tucumán colonial y en las pampas, Buenos Aires, Biblos, pp.79-114.

Boixadós, Roxana y Farberman, Judith, "Propietarios, agregados y Pobres de Jesucristo'. Tierra y sociedad en Los Llanos riojanos en el siglo XVIII", en Historia Agraria n. ${ }^{\circ}$ 54, Murcia, Universidad de Murcia, 2011, pp.41-70.

Boixadós Roxana y Farberman, Judith, "Tres formas de propiedad indivisa en La Rioja colonial. Mayorazgos, pueblos de indios y campos comuneros, siglos XVII a XIX", en Revista de Ciencias Sociales n. ${ }^{\circ} 27$, Bernal, Universidad Nacional de Quilmes, 2015, en prensa.

Canal Feijoo, Bernardo, "Teoría de la ciudad argentina", en Ensayos sobre cultura y territorio, Buenos Aires, UNQ/Prometeo 3010, 2010, p.143.

Chance, John y Taylor, William B., "Estate and Class in a Colonial City: Oaxaca in 1792", in Comparative Studies in Society and History n. ${ }^{\circ} 19$, Cambridge, Society for the Comparative Study of Society and History, 1977, pp.454-487.

Doucet, Gastón, "La administración de aguas en La Rioja bajo el régimen español: aportes para su historia", en Revista de Historia del Derecho n. ${ }^{\circ} 11$, Buenos Aires, Instituto de Historia del Derecho, pp.491-506.

Doucet, Gastón, "Las ordenanzas de aguas para La Rioja del visitador don Francisco de Alfaro (1611)", en Revista de Historia del Derecho n. ${ }^{\circ} 4$, Buenos Aires, Instituto de Historia del Derecho, 1976, pp.397-425.

Endrek, Emiliano, "La población de La Rioja en 1795. Análisis de un padrón eclesiástico", en Revista de la Junta Provincia de Historia de Córdoba n. ${ }^{\circ} 11$, Córdoba, Junta Provincial de Historia de Córdoba, 1986, pp.179-230.

Estenssoro Fuchs, Juan Carlos. "Los colores de la plebe razón y mestizaje en el Perú colonial”, en AAVV, Los cuadros de mestizaje del Virrey Amat. La representación etnográfica en el Perú colonial, Lima, Museo de Arte de Lima, 1999, pp.67-107 
Fernández Cháves, Manuel, "La Villa de Lebrija a finales del reinado de Felipe III. El padrón de Bula de Santa Cruzada de 1620", en Revista de Humanidades n. ${ }^{\circ} 16$, Sevilla, Universidad de Sevilla, 2009, pp.59-89.

Fradkin, Raúl, "Población y sociedad", en Jorge Gelman (coord.), Argentina. Crisis imperial e independencia. 1808-1830, Lima, Taurus, pp.193-242.

Guzmán, María Florencia, "Familias de esclavos en la Rioja tardocolonial (17601810)”, en Andes n. ${ }^{\circ} 8$, Salta, CEPIHA, 1997, pp.225-241.

Fradkin, Raúl, Los claroscuros del mestizaje. Negros, indios y castas en la Catamarca colonial, Córdoba, Encuentro Grupo Editor, 2010.

Herzog, Tamar, "La vecindad: entre condición, formal y negociación contínua. Reflexiones en torno de las categorías sociales y las redes personales", en Anuario IEHS n. ${ }^{\circ} 15$, Universidad Nacional del Centro de la Provincia de Buenos Aires, Tandil, 2000, pp.123-131.

Hudson, Nicholas, "From 'Nation' to 'Race': The Origin of Racial Classification in Eighteenth-Century Thought", in Eigteenth Century Studies vol.3, n. ${ }^{\circ} 29$, Baltimore, John Hopkins University Press, 1996, pp.247-264.

Larrouy, Antonio, Documentos del Archivo de Indias para la historia del Tucumán. Siglo XVIII, tomo II, Tolosa, 1927.

Levillier, Roberto, Nueva Crónica de la conquista de Tucumán, tomo III (15741600), Varsovia, Colección de Publicaciones Historia de la Biblioteca del Congreso Argentino, 1926.

Lorandi, Ana María, Poder central, poder local. Funcionarios borbónicos en el Tucumán colonial. Un estudio de antropología política, Buenos Aires, Ed. Prometeo, 2008.

Luna, Félix, "Planes para La Rioja colonial (1978)", en Temas de Historia colonial de La Rioja, La Rioja Nexus, 2004, pp.66-114.

Marchena, Juan, "Su majestad quiere saber. Información oficial y reformismo borbónico: el mundo andino bajo la mirada de la ilustración", en Procesos, Re-

Dossier: Cuestionando las fuentes de archivos: padrones de población, familias y sociedades coloniales en Iberoamérica, ss. XVIII-XIX 
vista Ecuatoriana de Historia n. ${ }^{\circ}$ 22, Quito, Universidad Andina Simón Bolívar, 2005, pp.45-83.

Marchionni, Marcelo, “Acceso y permanencia de las elites en el poder político local: El cabildo de salta a fines del periodo colonial.”, en Cuadernos de la Facultad de Humanidades y Ciencias Sociales n. ${ }^{\circ}{ }_{13}$, San Salvador de Jujuy, Universidad Nacional de Jujuy, 2000, pp.283-306.

Martínez de Sánchez, Ana María, "La Bula de Santa Cruzada. Córdoba del Tucumán en la segunda mitad del siglo Xviı!" en, Archivum n. ${ }^{\circ} 16$, Oviedo, Universidad de Oviedo, 1994, pp.297-312.

Ojeda Nieto, José, "La población de castilla y León en el siglo XVII: un intento de aproximación demográfica a través de la Bula de la Santa Cruzada", en Studia Histórica, Historia Moderna n. $^{\circ}$ 22, Salamanca, Universidad de Salamanca, 2000, pp.109-144.

Ojeda Nieto, José, "La población del Reino de Valencia en el siglo XVII según la Bula de la Santa Cruzada", en Estudis, Revista de Historia Moderna n. ${ }^{\circ} 32$, Barcelona, Universitat di Valencia, 2006, pp.263-320.

Quarleri, Lía, "La administración laica de los bienes de los jesuitas de La Rioja: producción, ingresos y malversación fiscal", en Mundo Agrario vol.1, n. $^{\circ}$ 2, La Plata, Universidad Nacional de La Plata, 2001, pp.1-17. http://www.mundoagrario.unlp.edu.ar/rt/printerFriendly/MAvo1no2a02/1573.

Quarleri, Lía, "Elite local, burocracia y reformas borbónicas: La administración de temporalidades de la Rioja”, en Población y Sociedad n.os8-9, Tucumán, Fundación Yocavil, 2000-2001, pp.177-210.

Rama, Angel, La ciudad letrada, Montevideo, Arca, 1998.

Rodríguez Molas, Ricardo, Los sometidos de la conquista. Argentina, Bolivia, Paraguay, Buenos Aires, CEAL, 1985.

Robledo, Víctor Hugo, La Rioja negra, Nexo Grupo Editor, La Rioja, 2004. 
Serrano Redonnet, Jorge A., La sangre del conquistador Juan Gregorio Bazán, Buenos Aires, Ed. Dunken, 1997.

Tío Vallejo, Gabriela, Antiguo Régimen y Liberalismo. Tucumán, 1770-183o, San Miguel de Tucumán, Universidad de Tucumán, 2001.

Zorraquín Becú, Ricardo, Los cabildos argentinos, Córdoba, Imprenta de la Universidad, 1956.

Zuñiga, Jean Paul, “’Morena me llaman...’ Exclusión e integración de los afroamericanos en Hispanoamérica: el ejemplo de algunas regiones del antiguo virreinato del Perú (siglos XVI a XVIII)", en Berta Ares Queija y Alessandro Stella (coords.), Negros, mulatos, zambaigos. Derroteros africanos en los mundos ibéricos, Sevilla, Escuela de Estudios Hispanoamericanos/csic, 2000, pp.105-122.

Dossier: Cuestionando las fuentes de archivos: padrones de población, familias y sociedades coloniales en Iberoamérica, ss. XVIII-XIX 